University of Louisville

ThinkIR: The University of Louisville's Institutional Repository

Electronic Theses and Dissertations

8-2016

\title{
Teacher self-perceptions and student academic engagement in elementary school mathematics.
}

Kathleen M. Cash

University of Louisville

Follow this and additional works at: https://ir.library.louisville.edu/etd

Part of the Curriculum and Instruction Commons

\section{Recommended Citation}

Cash, Kathleen M., "Teacher self-perceptions and student academic engagement in elementary school mathematics." (2016). Electronic Theses and Dissertations. Paper 2550.

https://doi.org/10.18297/etd/2550

This Doctoral Dissertation is brought to you for free and open access by ThinkIR: The University of Louisville's Institutional Repository. It has been accepted for inclusion in Electronic Theses and Dissertations by an authorized administrator of ThinkIR: The University of Louisville's Institutional Repository. This title appears here courtesy of the author, who has retained all other copyrights. For more information, please contact thinkir@louisville.edu. 


\title{
TEACHER SELF-PERCEPTIONS AND STUDENT ACADEMIC ENGAGEMENT IN
} ELEMENTARY SCHOOL MATHEMATICS

\author{
By \\ Kathleen M. Cash \\ B.S., Brescia University, 2004 \\ M.Ed., University of Louisville, 2012
}

A Dissertation Submitted to the Faculty of the

College of Education and Human Development of the University of Louisville in Partial Fulfillment of the Requirements for the Degree of

Doctor of Philosophy in Curriculum and Instruction

Department of Teaching and Learning

University of Louisville

Louisville, KY

August, 2016 



\title{
TEACHER SELF-PERCEPTIONS AND STUDENT ACADEMIC ENGAGEMENT IN
} ELEMENTARY SCHOOL MATHEMATICS

\author{
By \\ Kathleen M. Cash \\ B.S., Brescia University, 2004 \\ M.Ed., University of Louisville, 2012
}

A Dissertation Approved on

June 17, 2016

By the following Dissertation Committee:

Maggie B. McGatha, Co-chair

Jill L. Adelson, Co-chair

Jennifer M. Bay-Williams

Kate E. Snyder

Susan A. Peters 


\section{DEDICATION}

This dissertation is dedicated to my parents

Fred Cash

and

\section{Marilyn Terry}

who made it all possible 


\section{ACKNOWLEDGEMENTS}

I would like to thank many people for their help in the preparation of the dissertation. First, I thank my advisers Maggie McGatha and Jill Adelson for their years of support in my education and in the long process of piecing together this study. The many hours of helping with revision, data analysis, and all the nuts and bolts of this process have been much appreciated. But far more important to me has been their overwhelming support of and belief in my ability to complete this degree. I thank both of them deeply. Second, I thank the rest of my dissertation committee for the keen insights they have offered and their assistance in making the final product the best that it could be. Finally, I thank my family and my sisters who have been my biggest supporters since the beginning. In addition to being patient with my late hours of writing which have taken me from family and community gatherings, they have helped in innumerous ways from recruiting schools to putting together packets of surveys to taking my duties when I did not have time to fulfill them to simply offering prayers for my health and sanity. The love and support that I have received has made it all possible, and I am eternally grateful. 


\title{
ABSTRACT \\ TEACHER SELF-PERCEPTIONS AND STUDENT ACADEMIC ENGAGEMENT IN ELEMENTARY SCHOOL MATHEMATICS
}

\author{
Kathleen M. Cash
}

June 17, 2016

This study examined the relationship between elementary students' academic engagement in mathematics and their teachers' self-perceptions in mathematics. Early success in mathematics is seen as crucial for later success academically and professionally. Framed in Social Cognitive Theory this study sought to build on past research studies, which have found that student affective characteristics such as academic engagement, comprised of both behavioral and emotional engagement, vary across genders and ability levels. This study sought to use a number of control and independent variables to examine academic engagement in students and the relationship of that engagement to teachers' mathematics self-concept and teaching self-efficacy. Due to the nested nature of the data, hierarchical linear modeling was used to analyze the data.

Key findings indicated that, while classes of students vary on levels of academic engagement, in general this variability was not explained by the teacher's selfperceptions. However, when it comes to behavioral engagement, one of the two components of academic engagement studied here, in mathematics class, arguably a characteristic that might be particularly influenced by teachers, girls and boys 
differ significantly not only in their engagement (with girls in this study reporting statistically significantly more engagement than boys) but also in the way in which their engagement relates to teacher self-perceptions. In fact, teacher self-perceptions account for approximately $62 \%$ of the difference between girls and boys on their reported levels of behavioral engagement. Thus, the results of this study support the theory that, if one is interested in helping close the STEM gap for girls, there is a need for more mathematically strong teachers of female students even in the early grades. Suggestions for future research including looking at what class-level factors might explain the between-class variability in academic engagement, and further exploring the finding that differences in gender slopes were partially explained by teacher self-perceptions. 


\section{TABLE OF CONTENTS}

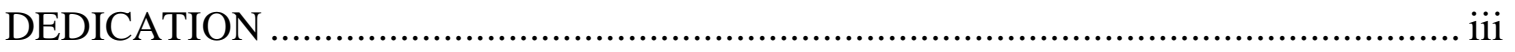

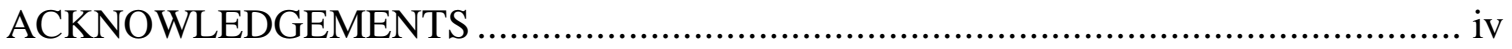

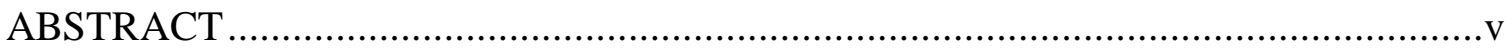

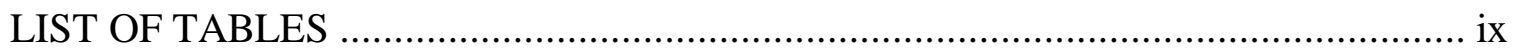

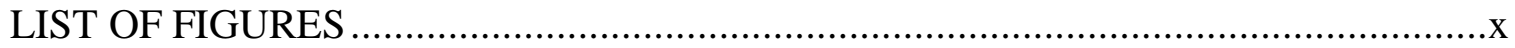

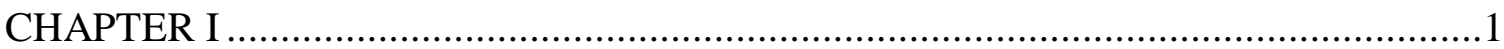

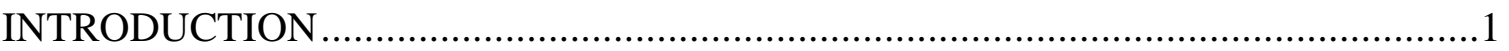

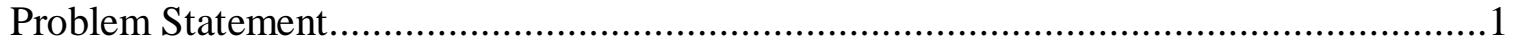

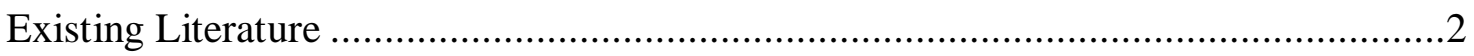

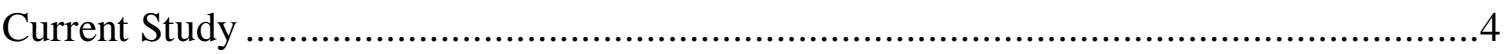

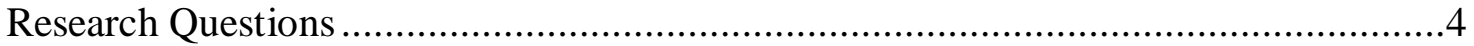

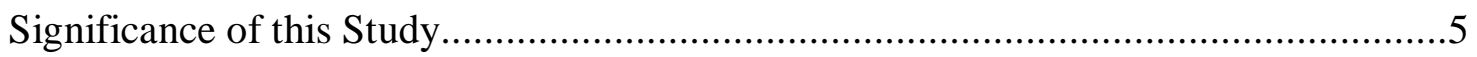

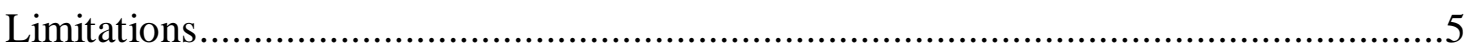

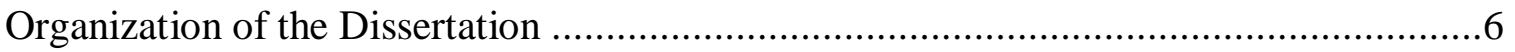

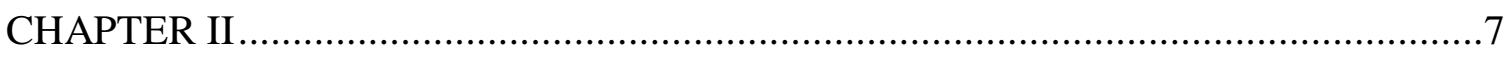

Theoretical Framework: Social Cognitive Theory ………..........................................11

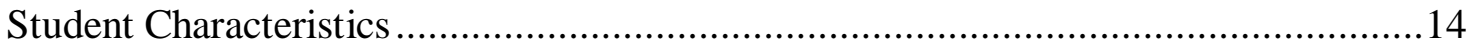

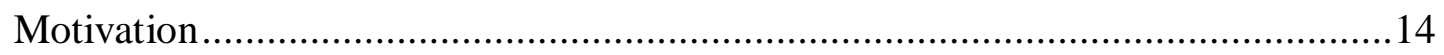

Student academic engagement .....................................................................15

Teacher Characteristics: Self-Perceptions ...........................................................27

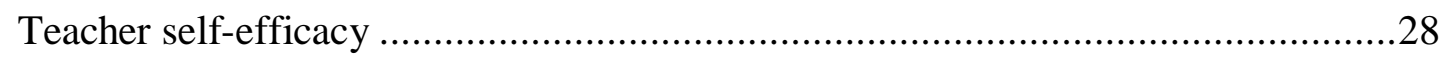

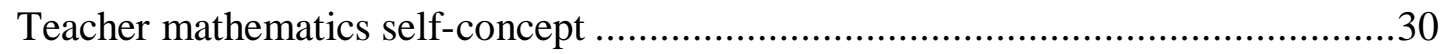

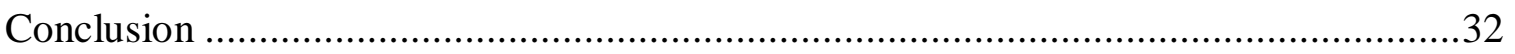

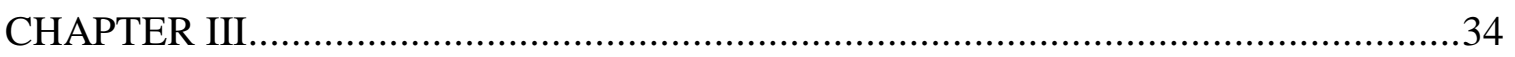

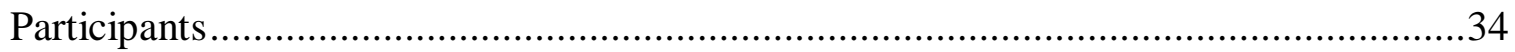

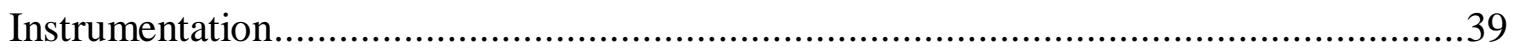




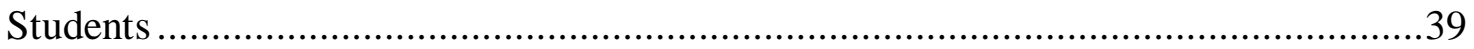

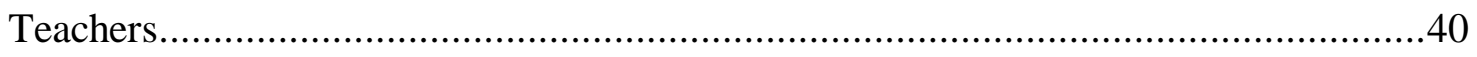

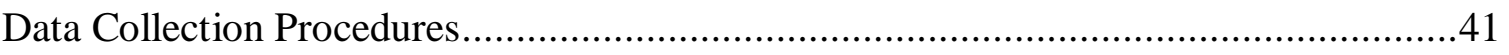

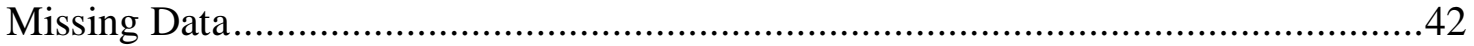

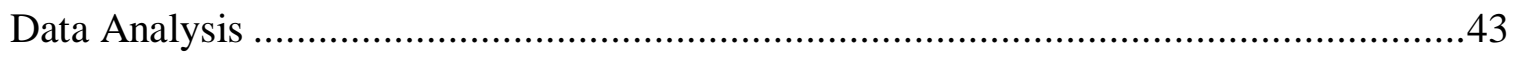

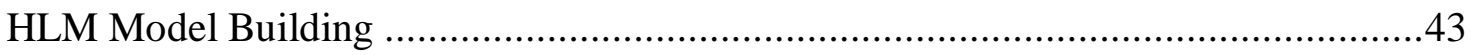

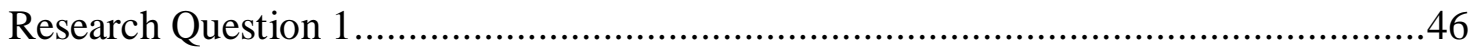

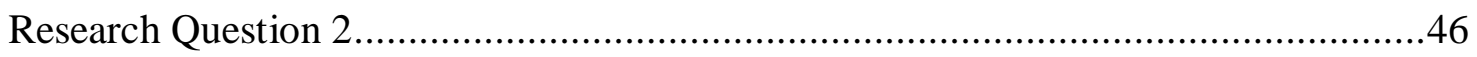

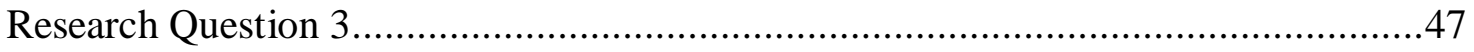

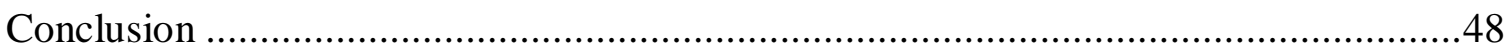

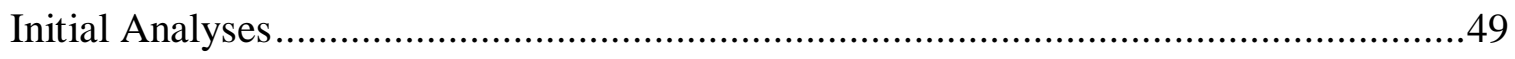

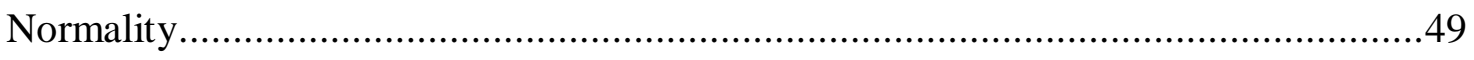

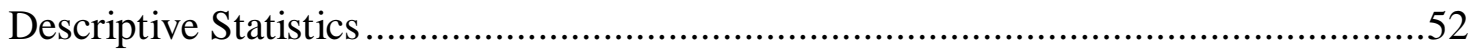

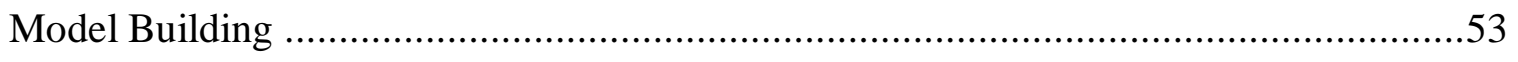

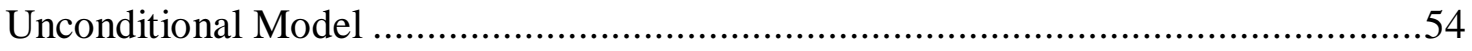

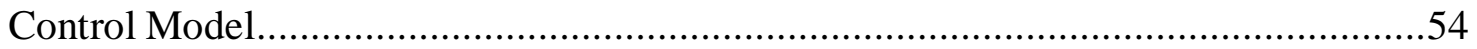

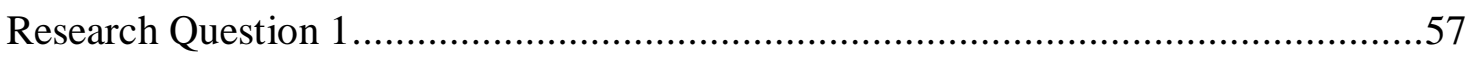

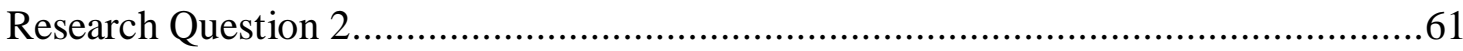

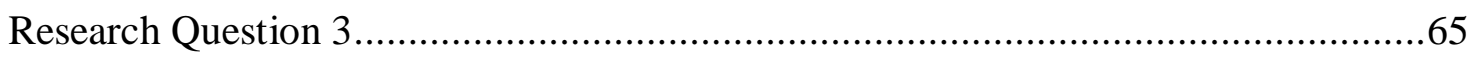

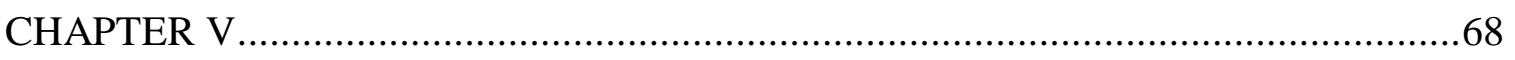

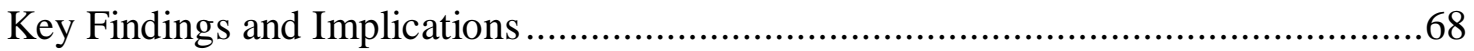

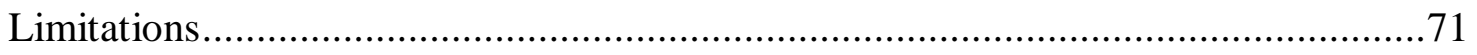

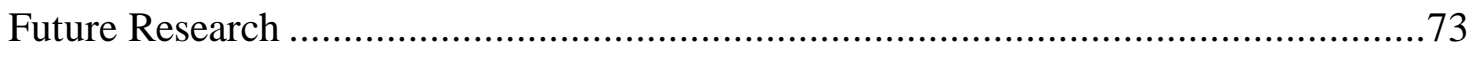

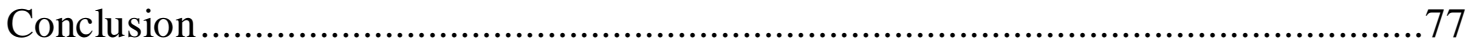

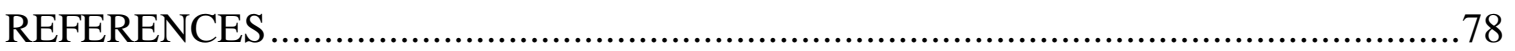

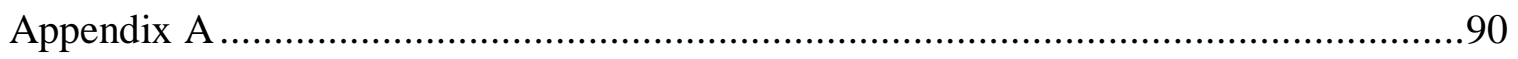

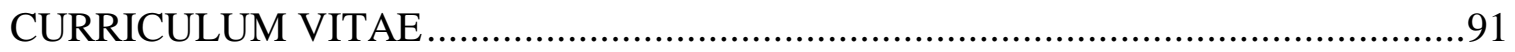




\section{LIST OF TABLES}

TABLE $\quad$ PAGE

1. Student-level Demographic Data ..................................... 38

2. Teacher and Class-level Demographic Data................................ 39

3. Variables for Analysis ................................................... 45

4. Descriptive Statistics for Student Outcomes ........................... 52

5. Descriptive Statistics for Teacher Outcomes............................ 53

6. Control Model for Behavioral Engagement .............................. 55

7. Control Model for Emotional Engagement ............................. 56

8. Contextual Model for Behavioral Engagement, Answering Research

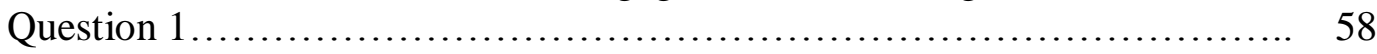

9. Contextual Model for Emotional Engagement, Answering Research

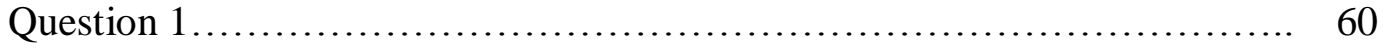

10. Contextual Model for Behavioral Engagement by Gender, Answering

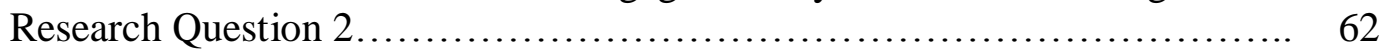

11. Contextual Model for Emotional Engagement by Gender, Answering Research Question 2 ........................................... 64

12. Contextual Model for Behavioral Engagement by Achievement Status, Answering Research Question 3 ..................................... 66

13. Contextual Model for Emotional Engagement by Achievement Status, Answering Research Question 3. 


\section{LIST OF FIGURES}

FIGURE $\quad$ PAGE

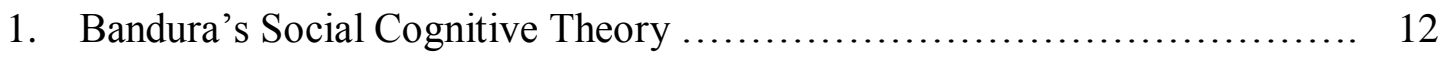

2. Social Cognitive Theory to Frame this Study ............................ 13

3. Histogram for Behavioral Engagement Outcome......................... 50

4. Histogram for Emotional Engagement Outcome............................ 50

5. P-P Plot for Behavioral Engagement .................................. 51

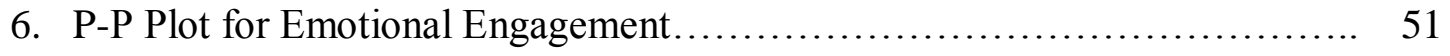

7. Predicted Values for Behavioral Engagement.............................. 62 


\section{CHAPTER I}

\section{INTRODUCTION}

This study examined the relationship between elementary students' academic engagement in mathematics and their teachers' self-perceptions in mathematics. The introduction to this dissertation describes the research problem, the existing literature used to frame the study, the purpose of the study, and the research questions.

Additionally, this introduction includes information about the significance of this study and the limitations of this study.

\section{Problem Statement}

Early success in mathematics is crucial for students' future successes in both academic and workplace environments (Levpuscek, Zupancic, \& Socan, 2012; Singh, Granville, \& Dika, 2002). Despite the importance of mathematics achievement, many American students struggle to keep up with their international peers (Adams et al., 2008). In past research studies, much attention has focused on achievement-related factors such as cognitive ability; however, more recent research endeavors have explored the effects of other student characteristics such as motivation and engagement (Levpuscek et al., 2012). One such affective characteristic is student academic engagement, a construct that is difficult to measure but has shown to coincide with increased achievement (Lange, 2010). Academic engagement is affected by the teacher's own abilities to create a productive learning environment which is also influenced by a teacher's self-perceived 
abilities to do so (Goddard, Hoy, \& Hoy, 2000). This study sought to explore the relationship between student academic engagement and teacher self-perceptions in an attempt to further understand the relationship between teacher characteristics and student attitudes. The following section of this introduction will provide a brief overview of the existence literature on academic engagement and teacher self-perceptions. Chapter 2 of this dissertation will offer a more in-depth look at existing literature.

\section{Existing Literature}

Academic engagement is a multi-faceted construct used to measure aspects of a student's participation in academic activities (Fredricks et al, 2004; Lee, 2014). Higher levels of engagement correlate to higher levels of achievement among many groups of students, including elementary students who tend to be most malleable in affective characteristics (Glanville \& Wildhagen, 2007; Levpuscek, Zupancic, \& Socan, 2012). Academic engagement is an important construct, especially in elementary students, because it is strongly correlated to academic achievement and increasing engagement might be one avenue through which schools can increase achievement (Fredricks et al, 2004). Although some student characteristics (e.g. ethnicity) remain stable over a time, schools might have influence on engagement (Fredricks et al, 2004). Because of the multidimensionality of engagement, engagement is frequently measured as a combination of several constructs (Betts, 2012). For the purpose of this study, engagement will be measured using the two-construct approach measuring both emotional and behavioral engagement as separate but correlated constructs. Though other aspects of engagement exist, the two discussed here are those which can be reliably measured in young children and which might correlate to academic success. Emotional engagement is the set of 
attitudes that a student has toward school (Fredricks, 2004). Emotional engagement might be considered the amalgamation of all the student's feelings around education (Betts, 2012). Behavioral engagement is the level of participation in academics (Fredricks et al, 2004). This facet might be further subdivided into categories such as following the rules or paying attention in class (Betts, 2012).

Because of its malleability, teachers have the ability to affect student academic engagement, thus, this study next looked at an important teacher characteristic: selfperceptions. Teachers who have stronger positive self-perceptions in teaching have been shown to use more all-encompassing teaching strategies that have been shown to engage students (Goddard et al., 2000). Self-perception is a broad category that encompasses both self-efficacy and self-concept (Adelson \& McCoach, 2011). Bandura (1977) defined self-efficacy as "the conviction that one can successfully execute the behavior required to produce the outcomes" (p. 287). The second component of self-perceptions for a teacher is self-concept. Self-concept is a "composite view of oneself that is presumed to be formed through direct experience and evaluations adopted from significant others" (Bandura, 1997, p. 10). One research study found that teachers who rank themselves higher on measures of teacher self-efficacy, often have more behavioral control of their classes and have students who are more actively participating in class- two aspects which might lead to increased academic engagement of students (Smith, 2010).

The above literature is used to frame the study described below. As it has been shown that increased academic engagement correlates to increased mathematics achievement, this study seeks to better understand what might help to affect the malleable construct of academic engagement. Teachers with stronger self-perceptions have been 
shown to use more skills desired of good teaching and thus might be able to affect change in student academic engagement. Guided by the past work, this study sought to test this relationship in elementary aged children it is essential to engage most students from an early age in order to foster later success in mathematics.

\section{Current Study}

The purpose of this study was to examine the relationship between teacher selfperceptions and student academic engagement. This study looked at teachers and their students in grades 3, 4, and 5 mathematics classes. In light of past research studies, which have found that student affective characteristics such as academic engagement vary across genders and ability levels, this study sought to use a number of control and independent variables to examine academic engagement in students. A detailed description of these variables is included in Chapter 3.

\section{Research Questions}

In order to explore the multiple relationships inherent in the proposed study, three research questions were developed. These research questions are:

1. What is the relationship between teacher self-efficacy and teacher mathematics self-concept and student emotional and behavioral academic engagement?

2. Does the relationship between teacher self-efficacy and teacher mathematics selfconcept and student academic engagement differ for boys and girls?

3. Does the relationship between teacher self-efficacy and teacher mathematics selfconcept and student academic engagement differ for students who are identified as academically high achieving? 


\section{Significance of this Study}

Past studies have shown that high levels of teacher self-perceptions have correlated to high levels of student academic engagement. However, many of these studies have been conducted only with older students. The current study sought to add to the body of existing literature by exploring the relationship between academic engagement and teacher self-perceptions with younger students. Additionally, this study adds several covariates and moderators including student gender, ethnicity, and academic ability and teacher mathematical background. By using many different covariates, I was able to add a great level of statistical control to the study, allowing me to make a stronger assertion on the relationship between the two variables of interest. Realizing that mathematics education in the United States has not yielded student achievement results that are up to par with much of the rest of the developed world, understanding of student motivation and academic engagement is a possible avenue to early intervention which may be implemented to help reverse the modern trend of United States mediocrity in mathematics.

\section{Limitations}

This study had limitations in two main areas: sample participants and lack of variability in the differential between high-achieving and non-high-achieving students. Though the sample size was deemed adequate for the type of study being conducted, all participants were drawn from the same Midwest area. Though one might generalize findings to other students in this geographic region, it is difficult to say if they would generalize to the full population. Additionally, the sample only included students in $3^{\text {rd }}$ $5^{\text {th }}$ grade. Findings might not hold for younger or older students. The teachers in the 
sample were overwhelmingly white, female teachers. As both race and gender tend to play a role in a person's self-perceptions, the use of teacher sample that was limited in diversity also affects the generalizability of the study. Additionally, though an effort was made to include a diverse student population, many of the public school students were eventually excluded from the study due to missing demographic data. Thus, many of the students more likely to come from ethnic minority groups are not included in the final analyses.

Second, this study did not capture a wide variety of types of classes; in particular, very few classes that participated in the study were ability-grouped. Past research has shown that attitudes (of which academic engagement is one) of high-achieving students are affected by ability-grouping (e.g., Marsh, 1987; Preckel \& Brüll, 2008). Because this study sought to examine the relationship between teacher self-perceptions and student academic engagement particularly among students who are high achieving, the lack of variability in class types suggests that the findings might only generalize to heterogeneous mathematics classes and not to ability-grouped classes.

\section{Organization of the Dissertation}

The organization of this dissertation is as follows: Chapter II provides a review of literature on motivation and academic engagement in the context of how these variables relate to mathematics education. Additionally, this chapter explores literature pertaining to teacher self-perceptions and their relationship to student engagement. Chapter III discusses the methodology used for analyzing the data collected from students and teachers. Chapter IV describes the results of the study. Chapter V concludes the study with discussion of key findings, limitations, and recommendations for future studies. 


\section{CHAPTER II}

\section{REVIEW OF THE LITERATURE}

Along with reading and writing, education systems world-wide have long considered the study of mathematics to be essential to a student's growth. In early educational history in the United States, much of what the ordinary student learned in mathematics could be reduced to arithmetic and geometry (Eddy et al, 2015). With the beginning of the Industrial Revolution came the dramatic need for increased understanding of higher levels of mathematics (National Research Council, 2007). Today, many aspects of everyday life rely on advanced technological feats that have been made possible through our understanding of mathematical applications (National Research Council, 2007). Mathematics achievement is seen as particularly important for the workforce (Levpuscek, Zupancic, \& Socan, 2012). From the economy to national security, we understand that the sciences, including mathematics, are essential in the modern world (Adams et al., 2008). A mathematically literate citizenry is necessary to continue the current rate of scientific discovery and growth that we have seen in last century (National Research Council, 2007).

In addition to preparing the future workforce, early foundations in mathematics are essential for students as they continue their educational studies. Because of its sequential nature, understanding and development of mathematical concepts, skills, and practices in early years is necessary for access to higher levels of study in the subject (Singh, Granville, \& Dika, 2002). Mathematics success has been found to be highly 
correlated to success in other school subjects, particularly in science (Singh et al., 2002). Also, measures of mathematics achievement play a large role in admission procedures to colleges and other postsecondary institutions (Levpuscek et al., 2012), and mathematics is needed for many careers and serves as a gateway for science-related jobs (Nosek \& Smyth, 2011). Thus, even though most students do not plan to enter a field that is explicitly related to mathematics, many will find the study of mathematics as essential to their future plans.

In addition to the notion that mathematics is of great importance to promotion of the common good and to one's future studies, some believe that the study of mathematics is useful simply for the sake of study. Dating back for more than 5000 years, mathematics has been studied and taught across various civilizations, at times for specific purposes (e.g., arithmetic or architecture) but often simply for the intellectual growth that its study offers (Debnath, 2011). Others would argue that the study of mathematics is important because it helps students to increase problem solving skills in a variety of endeavors and also helps to develop critical thinking (Schoenfeld, 1992). Whether we study mathematics for its own beauty or for the sake of increasing our own reasoning skills, the study of mathematics is an integral part of today's society.

For centuries, education in the sciences and mathematics has been touted as important to modern life. Although the United States, like many countries throughout the world, has recognized and responded to the necessity of the changing times and the everincreasing need for strong mathematics programs, students in the United States do not perform as well on international measures of mathematics achievement as do students in many other similarly-developed nations on average (Adams et al., 2008; National 
Research Council, 2007; Schoenfeld, 1992). In the most recent reports from administration of the triennial survey Programme for International Student Assessment (PISA), the United States placed $27^{\text {th }}$ out of 34 developed nations in mathematics, and $26 \%$ of students in the United States did not score at the proficient level as rated by the program (OECD, 2013). These standings are not new for students in the United States. On the 1995 version of the Trends in International Mathematics and Science Study (TIMSS), the most mathematically advanced students in the United States, that is, the 5\% of students taking AP Calculus, did not score as well on average as their similarlyadvanced foreign counterparts (Adams et al., 2008). Clearly, advanced status does not help students in the United States to keep up with their peers. Of the 26 countries that score higher than the United States on the mathematics portion of the 2012 PISA, only four countries spend more money per student than does the United States (OECD, 2013). Additionally, in the case of most countries, the overall economic state of the nation is a strong correlate with achievement scores, however this does not hold for the United States (OECD, 2013).

With the recognition that mathematics education is important for the future of the country, more must be known about ways in which we can help American students to succeed. Some of the past correlational research in the area of mathematics education has focused on factors that cannot be controlled. These factors include constructs such as socioeconomic status, gender, and ethnicity (Levpuscez et al., 2012). Although this information has been helpful in building programs that attempt to reach students in those categories that are least likely to reach their full potential (Adams et al., 2008), achievement gaps still exist between American students and those in the rest of the world. 
Some recent research studies have looked at relationships between achievement and affective characteristics of students, such as academic engagement, a subcategory of motivation (Levpuscek et al., 2012). This affective category of characteristics has been chosen because it offers another avenue by which to explore better ways of reaching all students (Singh et al., 2008). The construct of academic engagement encompasses a variety of attitudes toward scholarly endeavors, including emotional attitudes toward classes and the behaviors in which one chooses to engage in class (Fredricks et al., 2004). These engagement traits are seen as more malleable characteristics of students than socioeconomic status or ethnicity, and thus schools and educators have more ability to affect change in them (Singh et al., 2002). However, research has shown that, by the end of high school, most students have developed a stable evaluation of their attitude toward mathematics (Middleton \& Spanias, 1999). Thus, understanding of elementary students' academic engagement is essential so that early intervention with students in terms of academic engagement may be implemented to help reverse the modern trend of United States mediocrity in mathematics.

In addition to the study of student affective characteristics, teachers also have important traits that can be affected through training and education. This study will focus on one such characteristic: self-perceptions. This category of affective teacher characteristics was chosen because it is correlated with productivity (Marsh \& Byrne, 2003) while being easier to measure than teacher actions. Teacher self-perceptions is a broad category that is defined as a construct including both self-efficacy and self-concept (Adelson \& McCoach, 2011). Teacher self-efficacy is considered to be one malleable characteristic of teachers (Dellinger, Bobbett, Olivier \&Ellet, 2008). A teacher's sense of 
self-efficacy has been found to predict both that teacher's use of innovative teaching techniques and student academic achievement (Ross, 1992). As the use of a wide variety of creative teaching techniques has been shown to increase student academic engagement (Adams et al., 2008), one might find that teachers with high self-efficacy help to raise their students' levels of engagement. Alternately, self-concept refers to an individual's beliefs in their ability to complete a specific set of tasks (Bandura, 1997). Though selfconcept is not as strongly correlated with increased performance as is self-efficacy, there is a positive relationship, particularly when a person with high self-concept also possesses a high level of self-efficacy (Bandura, 1997). Given this background, it makes sense that this study is grounded in Bandura's Social Cognitive Theory.

\section{Theoretical Framework: Social Cognitive Theory}

Social Cognitive Theory (Bandura, 1997) suggests that learning takes place in a social context involving personal factors, environment, and behavior. Though earlier behavioral researchers had posited that the environmental factors had a one-way causal relationship with the behaviors, Bandura's updated theory suggests that the relationships among the three factors (teacher self-efficacy, teacher mathematics self-concept, and student academic engagement) are reciprocal, thus each affects the other two in varying ways (Bandura, 1997). For Bandura, personal factors include the internal such as motivation, self-efficacy, and cognition. Behavior in the Bandura model includes the action actually taken in the social system. The environment describes the external factors that affect one's thoughts and actions. Figure 1 shows Bandura's model. 
Figure 1. Bandura's Social Cognitive Theory

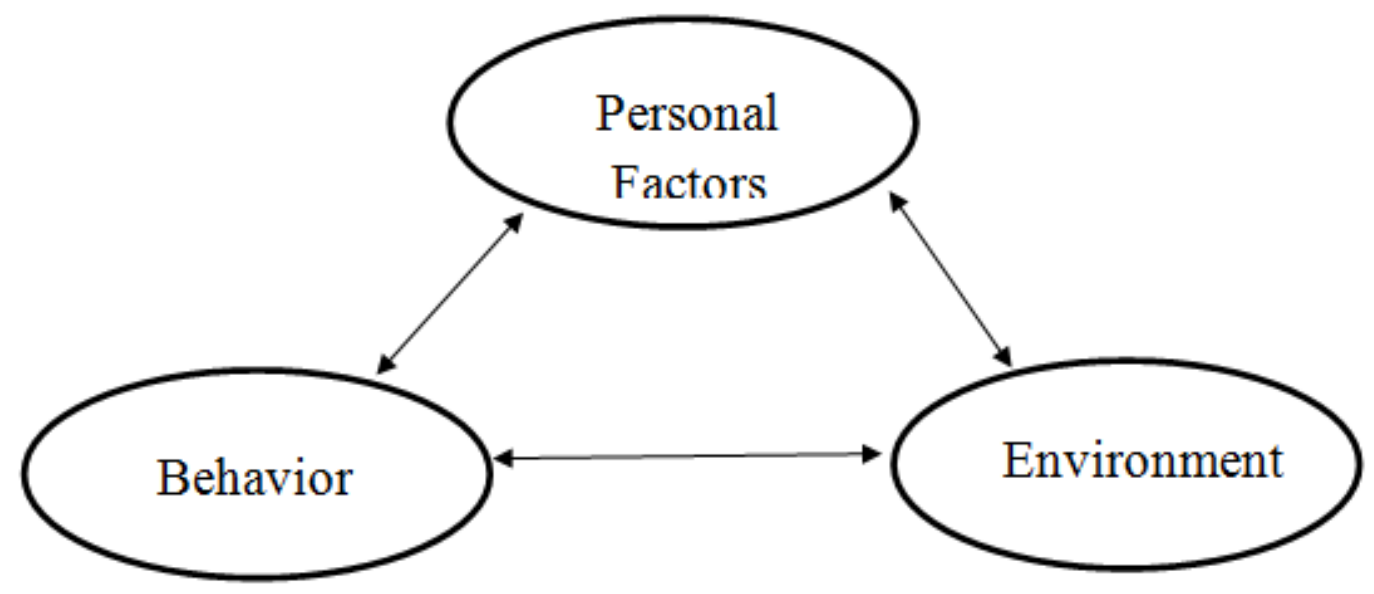

In this study, I will use Bandura's theory to model the relationships among the affective characteristics of student academic engagement, teacher self-efficacy, and teacher mathematics self-concept described above that are implicit in the classroom environment. Figure 2 shows how the three classroom affective characteristics relate to the Social Cognitive Theory. 
Figure 2. Social Cognitive Theory to Frame this Study

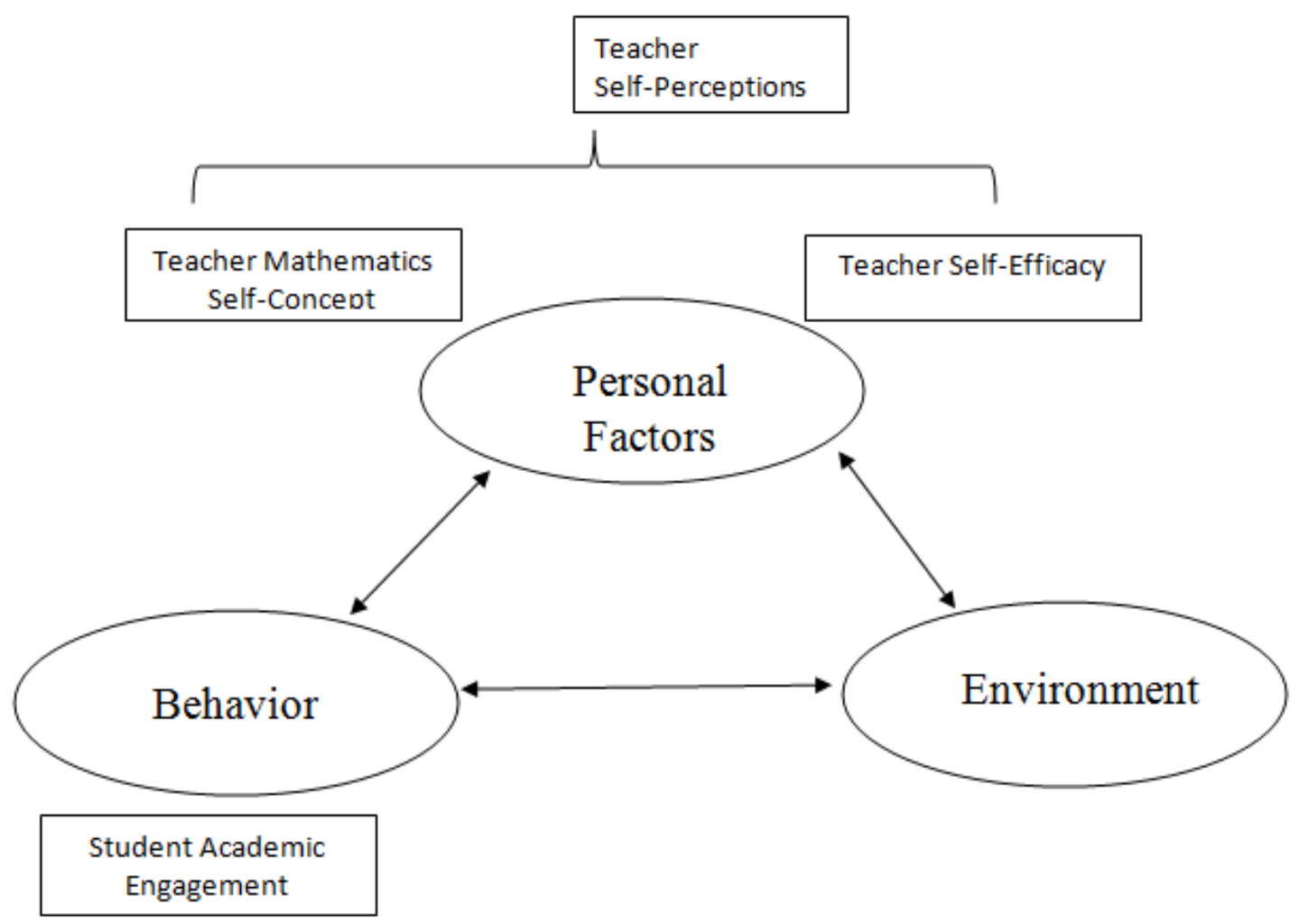

When viewing this from the perspective of the teacher as the person, there are certain environmental characteristics that affect the teacher. For example, teacher mathematics self-concept is a personal factor that is environmentally influenced, because self-concept is externally defined by those in the environment. Teacher self-efficacy would fall into the place of Bandura's category of personal factors, because teacher selfefficacy describes the teacher's personal internal sense of their ability to teach mathematics. Student academic engagement falls under Bandura's category of behavior, because it describes students' engaged behavior in the classroom. In the reciprocal nature of SCT, the actions or attitudes of students in the classroom influence the classroom environment and also the teacher's self-perceptions. Conversely, the teacher's self- 
perceptions also influence student behavior (i.e. engagement) and the classroom

environment. Together the three work together to define the classroom system for these students and teachers for this class.Each of these factors will be described in more detail in the following sections.

Thus, this chapter includes a review of research on student characteristics of (1) academic engagement, and teacher characteristics of (2) self-efficacy and (3) mathematics self-concept in order to develop a framework for the research that was conducted.

\section{Student Characteristics}

The first affective characteristic to explore is student academic engagement. However, in order to fully understand academic engagement, we must first describe the broader context from which it has been defined. Student academic engagement derives from the larger category of motivation, which will be described first before more fully delving into the definition of student academic engagement.

Motivation. Motivation comes from the Latin word for "to move," and encompasses a person's desire and willingness to move into action (Eccles \& Wigfield, 2002). Motivation is a multi-faceted construct that has been studied extensively in recent years in relationship to success. High levels of motivation have been found to be highly correlated with academic achievement (including mathematical achievement), and thus motivation is a popular field in modern educational research (Green, Martin, \& Marsh, 2007). In addition to its strong relationship with academic success, studies have shown that student motivation is highly correlated with academic self-concept. It is possible that 
motivation helps to mediate the effect of academic self-concept on student engagement and academic achievement (Green et al., 2012).

Today, most theories of motivation relate to how an individual's beliefs or goals move one to action (Eccles \& Wigfield, 2002). Though motivation is sometimes measured dually as intrinsic or extrinsic (Ryan \& Deci, 2000), motivation is frequently subdivided into a variety of smaller categories, (e.g., engagement, future aspirations, and persistence) (Fredricks, Blumenfeld, \& Paris, 2004; Green et al., 2007). Recent motivation theories are focused on expectancy or a person's perceived ability to complete a task while other theories are focused on reasons why a person might be motivated (Eccles \& Wigfield, 2002). Motivation has been subdivided into a variety of categories, making the task of studying motivation quite challenging. In this study, motivation will be viewed through the framework of academic engagement, one of its components. Studying the many facets of motivation is beyond the scope of this project, but, as academic engagement is an important factor, this study will focus solely on engagement. Thus, all measurement of motivation will be conducted through the measurement of academic engagement as defined below.

Student academic engagement. Academic engagement, alternately referred to as school engagement or student engagement, is a multi-faceted construct used to measure various aspects of a student's participation, commitment, and involvement in academic or school-based activities (Fredricks et al., 2004; Lee, 2014). In many recent studies, academic engagement has been found to be highly correlated to academic achievement (Fredricks et al., 2004) and, in particular, mathematics achievement (Singh, Granville, \& Dika, 2002). Although the construct of academic engagement has received increased 
interest from researchers in the last several years, accurate measurement of the construct remains difficult (Fredricks et al., 2011). Because of the multidimensionality of academic engagement, it is frequently measured as a combination of several different constructs (Betts, 2012).

One of the most respected approaches to defining and measuring engagement stems from the work of Jennifer Fredricks. Based on her work some current instruments are using a three-construct approach to measure engagement: behavioral, cognitive, and emotional (Lee, 2014). Although some instruments use the three-construct approach, other instruments measure only two constructs. In many instruments that measure only two aspects of engagement, cognitive and behavioral engagement tend to get consolidated into what some researchers call psychological engagement (Betts, 2012). Particularly for younger students, that is, students in the kindergarten through $5^{\text {th }}$ grades, measurement regarding issues of cognitive engagement is difficult (Fredricks et al., 2011), thus some scales do not include the cognitive component at all. Because the psychological construct of academic engagement is inherently an internally understood characteristic of students (Fredricks et al., 2004) and because young children have difficulty in recognizing components of cognitive engagement such as perseverance and ingenuity (Betts, 20120), it is incredibly difficult to obtain an accurate rating of a young child's cognitive engagement. In this study, I will be using a two-construct approach, focusing on behavioral and emotional engagement.

Measurement of student academic engagement. The first hurdle to adequate measurement of academic engagement is to develop appropriate operational definitions for those aspects of engagement that are to be measured (Betts, 2012). The reader will 
recall that for this study, academic engagement will be measured on the two constructs of behavioral and emotional engagement.

Behavioral engagement is frequently measured as the level of participation in academic activities (Fredricks et al., 2004). This measure of behavioral engagement might be further subdivided into categories such as (a) following the rules, (b) paying attention, and (c) arriving at school on time and prepared for class (Betts, 2012).

Glanville and Wildhagen (2007) measured behavioral engagement by asking students to respond to questions related to how often they show up for class with the items that are necessary for that class and with questions about how other students or teachers might view their behavior during class. Alternatively, other instruments, such as the Academic Engagement Scale of the Consortium on Chicago School Research and the School Engagement Questionnaire, measure behavioral engagement with items relating to attention by asking students to report on how carefully they attend to lessons during class, or what types of distractive behaviors they might engage in during school time (Fredricks et al., 2011).

Emotional engagement is the attitude that a student has toward school (e.g., assigned classes or school activities) or towards those people involved in the school (e.g., teachers or other students) (Fredricks et al., 2004). In essence, most researchers consider emotional engagement to be the combination of all of a student's feelings toward the school setting (Betts, 2012). Additionally, emotional engagement encompasses the sense of belonging a student might feel within the educational environment (Appleton, 2006). Items that measure emotional engagement might focus on a student's feelings toward school in general with items such as "I feel happy when I am at school" (Fredricks et al., 
2011). Additionally, emotional engagement items might measure the extent to which a student enjoys a particular class or a particular subject, for example, "I enjoy going to math class" (Betts, 2012). Finally, emotional engagement has, at times, been measured by asking students to rate their sense of belonging in a classroom. For example, a student might be asked to respond to the item, "I feel like my thoughts are valued in this class" (Fredricks et al., 2011).

Challenges in measuring academic engagement. Though the study of academic engagement offers valuable insight into a student's actions in and feelings toward school, the construct itself is difficult to measure (Fredricks et al., 2011). One major issue in the measurement of academic engagement is that the construct is both subject and environment specific (Betts, 2012). While measuring academic engagement, researchers need to be aware that students might answer differently depending on the subject identified in the questions and the manner in which questions are asked (Betts, 2012). Also, self-reports of academic engagement vary across different groups of students. For example, a student might respond with a very high level of academic engagement when asked to report on school-level factors but might respond with very low levels of engagement when asked about a specific subject or a class-level factor (Wang, Bergin, \& Bergin, 2014). An additional issue in the measurement and understanding of academic engagement is that the role it plays differs among students in different demographic groups. The next two sections of this paper describe these two issues and how they relate specifically to mathematics.

Measurement of academic engagement in mathematics. Because academic engagement is subject and environment specific, individual instruments must be used to 
measure the construct in different (a) subjects and (b) populations. A 2011 study conducted by Fredericks searched for measures of engagement aimed at middle-grades students ( $4^{\text {th }}$ through $8^{\text {th }}$ grades $)$ and found no fewer than 156 instruments claiming to measure academic engagement. Thirty-one of these 156 were discarded because they did not measure engagement as defined by the researcher and others were excluded because they did not meet the age ranges of interest (Fredricks et al., 2011). From the comprehensive search, Fredricks and colleagues retained only 21 instruments that they believed to accurately measure academic engagement for students in this age range. Of those 21 instruments, only one measured academic engagement in mathematics (Fredricks et al., 2011). Other researchers have found a void in the measurement of academic engagement in mathematics in elementary school students (Betts, 2012). More recent research has focused attention on developing scales for mathematics in an attempt to fill the instrument void for a scale to be used with young children (Cash, 2015).

In addition to measuring academic engagement relative to subject (in this case, mathematics), environmental characteristics should be explored. Some of the most commonly explored environmental characteristics include gender, socioeconomic status, academic ability, and ethnicity. For the focus of this study, I will look specifically at two characteristics (gender and ability) and how they affect motivation and academic engagement. These two characteristics were chosen because a great deal has been hypothesized about the impact of these attributes on both achievement and engagement (Nosek \& Smyth, 2012), and this study seeks to further explore their relationship to the construct of interest. 
Prior research has demonstrated that levels of motivation are not equal between genders. In mathematics in particular, although girls and boys tend to achieve at roughly the same levels in mathematics, girls rank themselves as less motivated in the subject (Leaper, Farkas, \& Brown, 2012). Additionally, a study of peer, school, and parent influences on motivation and engagement found that peers have the strongest effect on academic engagement, often in the negative direction (Ganotice \& King, 2014). For adolescent girls, the effect of peer pressure may have an even more detrimental effect on motivation and enjoyment in mathematics (Leaper et al., 2012). As so many talented girls are seen dropping out of the science-related fields (which includes mathematics) (Rinn et al., 2008), more research into enjoyment and motivation is needed to help educators and school systems find ways for encouraging young girls to remain interested in the mathematics.

Many researchers offer suggestions as to why girls are less motivated or engaged in general. In mathematics, as in many other subjects, girls are more likely to be influenced by their own failures than boys. This sense of failure in girls might be compounded by the way in which girls see themselves relative to classmates (Rinn et al., 2008). Particularly in science and mathematics, girls tend to compare their achievement with classmates, and, when they do not do as well as another, are more likely to choose not to engage in those subjects (Rinn et al., 2008). This feeling of failure extends to gifted girls as well. Preckel and Brüll (2008) found that academically gifted girls placed for the first time in an ability-grouped classroom did, in fact, show more significant negative changes in their academic self-concept than did boys' experiences in the same change. 
In addition to differences between boys and girls in measures of motivation and academic engagement, students of different academic abilities also have differing levels of motivation. In general, student motivation increases when students are given tasks that they feel they are capable of completing with some level of success (Banda, Matuszy, \&Therrien, 2009). Thus, academically gifted students tend to have higher levels of motivation then do some of their peers (Trautwein, Lüdtke, Marsh, Köller, \& Baumert, 2009). However, this relationship between ability and motivation is mitigated in certain situations, particularly depending on whether classes are ability grouped.

The sections above have demonstrated the importance of measuring students' academic engagement in mathematics. Research has shown that increased academic engagement has correlated to increased academic achievement (Green et al., 2007). Additionally, an increasing number of instruments have been developed for the purpose of measuring academic engagement, which has aided researchers' ability to study academic engagement among students (Fredricks et al., 2011). As academic engagement is an affective characteristic that can be influenced by environmental conditions including the teacher (Singh et al., 2002), the next focus of this chapter will look at the teacher as an influence of academic engagement in mathematics.

The teacher's influence on academic engagement in mathematics. Middleton and Spanias (1999) contend that much of the reason for students' lack of motivation, engagement, or enthusiasm for mathematics stems from lack of teacher support in mathematics. In general, Middleton and Spanias (1999) offered three key guidelines for increasing students' motivation to do mathematics. These guidelines are:

1. Problems should not be too difficult that the student feels they are unmanageable. 
2. Activities should be meaningful to the students now or in the future.

3. Teachers should offer incentives such as praise or concrete rewards.

This section will explore the ways in which the teacher is key in increasing motivation and student engagement in mathematics based on these three guidelines.

The first suggestion of Middleton and Spanias (1999) is that teachers should know their students' ability well enough to provide problems that are challenging and yet manageable for the students. Banda et al. (2009) add to this the idea of using the HighPreference strategy, in which problems that students are more likely to complete are placed first and then followed by more difficult or lower-preference problems. When students are faced with problems that they feel they can complete, they are more likely to remain engaged and motivated to complete the rest of the task (Middleton \& Spanias, 1999). In order to incorporate these strategies appropriately in the classroom setting, teachers must feel confident in their ability to design such work assignments for students and also in their ability to evaluate the effectiveness of such a program (Banda et al., 2009).

Another strategy that teachers can utilize to make tasks more manageable for students is the use of calculators or other technology, which may help achieve the goal of reaching all learners by removing some of the tedious calculations which may inhibit students. As an example, Kissane (2007) notes that, in the learning of applications of matrices, students could spend a great deal of time memorizing methods for reducing a matrix to row-echelon form. Kissane asserts teachers may allow students to use technology for the reduction, thus allowing more time to understand the meaning of particular solutions (2007). In another study, Oates (2009) notes that some students have 
had difficulty learning calculus and differential equations because the procedural mathematics posed too much of a stumbling block. The use of computer algebra system software can help remove this obstacle and support students in developing a conceptual understanding of the calculus material. However, the use of such technology, even in the earliest grades, is sometimes thwarted by a teacher's lack of understanding or confidence in correctly implementing its use (Ellington, 2003).

The second key to increasing motivation to do mathematics, according to Middleton and Spanias (1999), is to ensure that the tasks in which students engage are meaningful now or in the future. Thus, another way in which to increase behavioral engagement in students is by offering the students a greater capacity to interact with meaningful mathematics. Student interaction with mathematics is a vague construct. Dede (2000) offers some broad categories of ways through which students may interact with mathematics. These include designing lessons through which students are expected to perform tasks such as extrapolating rules through modeling; discovering mathematical theorems and concepts through inquiry-based learning; using special methods to ensure that lessons reach all students; offering students authentic problems to solve; and allowing students to partner with teachers or in the learning experience (Dede, 2000). Some very simple examples of interaction with mathematics include using manipulatives to represent number concepts, modeling an authentic problem using an equation, or finding a variety of methods for solving a problem (Schoenfeld, 1992). Students who engage in these types of activities are better equipped to find patterns, think, reason, conceptualize material, and use available resources to solve problems (Henningsen \& Stein, 1997). Teachers play a lead role in facilitating the interaction of mathematics in 
this way, as they must ensure that the tasks are mathematically sound while still being within the students' reach (Henningsen \& Stein, 1997).

Finally, Middleton and Spanias (1999) suggest that teachers offer incentives or rewards for students to remain motivated in the learning of mathematics. Teachers must find appropriate strategies for using rewards to keep students meaningfully interested in the subject (Rodrigo, 2011). The use of many new technology tools has been shown to engage students behaviorally in a variety of different ways with mathematics curriculum. Students tend to enjoy using technology in general and thus have a heightened interest in using it for educational endeavors (Bebell \& O’Dwyer, 2010). Because of its adaptive ability, technology can increase attitudes of students and increase motivation to complete activities (Halat, 2008). Research indicates that games increase the amount of time that students voluntarily spend on task both inside and outside the classroom. The reward of winning an electronic game or achieving a new level motivates some students to persist in playing games, even when the game consists of work that student might otherwise find unpalatable, such as mathematics for some students (Rodrigo, 2011).

It is clear from the previous paragraphs that teachers can play a key role in keeping students motivated in mathematics. Researchers also offer a variety of ways in which teachers can influence other aspects of academic engagement in the study of mathematics. The reader will recall that this study is focusing on two constructs of academic engagement: behavioral and emotional engagement.

Methods for increasing behavioral engagement might seem more obvious to teachers than ways one might increase emotional engagement. One key example of the behavioral component of academic engagement that teachers can influence is student 
time-on-task. Researchers have defined time-on-task differently but, for this study, timeon-task will mean time spent working on teacher-directed or approved academic activities (Mifsud \& Mørch $\dagger, 2010)$. These on-task behaviors might include activities such as reading, completing paper assignments, reviewing teacher feedback of work, or using manipulatives or technology that might aid in discovery of knowledge (Mifsud \& Mørch $\dagger, 2010)$.

The second aspect of academic engagement is emotional engagement, which encompasses the students' thoughts and feelings toward and enjoyment of a subject or class (Fredricks et al., 2004). One way to increase a student's emotional engagement is to increase the enjoyment of the class. One way that a teacher can do this while still maintaining a strong academic environment is through the playing of games which have been shown to help all students to better enjoy class, particularly when such games do not overdo the "drill and kill" model of procedural mathematics (Rodrigo, 2011). The playing of quality games has shown to have some effect in helping students who are visioauditory learners (Rapp, 2009). Some games provide a visual depiction, which students can use to grow in understanding (Rapp, 2009). Games also offer immediate feedback to students, which may aid in confidence-boosting (Rodrigo, 2011). Finally, games provide incentive to complete school-based activities, an important aspect particularly for students with learning disabilities (Banda et al., 2009). Because of these factors, games appear both motivating and educationally effective, particularly for younger learners (Rodrigo, 2011).

Another way in which effective teachers might increase student emotional engagement is through the use of problem-based learning (PBL). PBL is student-centered 
approach to teaching that gives students scenarios in which they can construct knowledge in a particular discipline like mathematics (Jerzembek \& Murphy, 2013). Scenarios used in PBL often do not specify specific algorithms for solving and they often have complex solutions. Because PBL is not constrained by the normal requirements of developing a problem with a "nice" solution, cases used in PBL tend to be more similar to those problems at student might encounter in the real world (Cerezo, 2004). The benefits of this are twofold. Firstly, many students find these real world style problems more interesting and engaging than those typically encountered in a traditional mathematics textbook (Cerezo, 2004). Secondly, the real-world problems in which students are called to engage ask them to use skills that are more applicable to a variety of settings. That is, students are not always confined to a single technique for solving and thus PBL opens more opportunities of entry into the problem solving process. These multiple avenues of entry can invite students of all levels and abilities to make attempts at PBL (Trinter, 2015). A survey of PBL research noted that these multiple entry points serve as a source of increased self-confidence in students, which may then increase the student's emotional engagement (Hung, Jonassen, \& Liu, 2008).

This concludes the first section of the review of the research focused on the student characteristics of motivation and academic engagement. Next the review of research on the teacher characteristic of self-perception is presented. For this study, this construct is subdivided into the constructs of (1) self-efficacy and (2) mathematics selfconcept. 


\section{Teacher Characteristics: Self-Perceptions}

A teacher's thoughts about the usefulness of mathematics as well as that teacher's beliefs about the best ways in which mathematics should be taught play a pivotal role in the motivation of students within the classroom (Middleton \& Spanias, 1999). In general, self-perception is considered to encompass how a person views their abilities to teach in alignment with their core set of beliefs. According to Adelson and McCoach (2011), selfperception can be subdivided into self-efficacy and self-concept. The first important component of self-perceptions is that teacher's own self-efficacy (Tschannen-Moran, Hoy, \& Hoy, 1998). Bandura (1977) defined self-efficacy as "the conviction that one can successfully execute the behavior required to produce the outcomes" (p. 287). Increased levels of self-efficacy increase the probability that one will attempt to implement new and innovative behaviors (Ross, 1992).

The second component of self-perceptions for a teacher is self-concept. Selfconcept is a "composite view of oneself that is presumed to be formed through direct experience and evaluations adopted from significant others" (Bandura, 1997, p. 10). Where self-efficacy looks at a teacher's perceived abilities, in general, to be a good teacher, self-concept is domain-specific and relates to a person's perceptions of his or her ability to accomplish a particular task (Pajares \& Miller, 1994).

Past research has suggested it is important to consider the implementation of a variety of teaching methods in order to increase student motivation and academic engagement and that adequate mathematical knowledge is necessary for this implementation (Middleton \& Spanias, 1999). Because teachers with higher selfperceptions are more likely to engage in a variety of teaching methods owing to their 
increased confidence (Goddard, Hoy, \& Hoy, 2000) this section will explore two specific types of self-perceptions related to the teaching of mathematics: teacher self-efficacy and mathematics self-concept. Teacher self-efficacy here refers to an individual's beliefs about their knowledge of the pedagogical skills necessary teach to students. Mathematics self-efficacy here refers to a teacher's belief that they understand mathematical concepts and how to transfer those concepts to their students (McGee \& Wang, 2014).

Teacher self-efficacy. As it has been found that affective teacher characteristics (such as self-efficacy) have one of the largest effects on motivating and engaging students, and ultimately, leading students to achievement (Smith, 2010), recent studies have turned their attention to individual teacher characteristics. The study of teacher selfefficacy is of interest in this discussion as it has been shown that more self-efficacious teachers tend to be more persistent in efforts at classroom management and utilizing innovative teaching techniques (Goddard, Hoy, \& Hoy, 2000). Additionally, teachers who rank themselves higher on measures of teacher self-efficacy often have more behavioral control of their classes and have students who are higher achievers (Smith, 2010). Teachers with more self-efficacy for teaching mathematics have been found to be more persistent in working with students and more open to new ideas and techniques (Nurlu, 2015). Because the use of innovative teaching practices and classroom management strategies are theorized to increase student academic engagement and because the more self-efficacious teacher is most likely to feel confident in incorporating these techniques, self-efficacy is an important variable to consider when looking at ways to increase student motivation and academic engagement. 
The definition of teacher self-efficacy has developed over many years of research and writing (Goddard, Hoy, \& Hoy, 2000). In fact, what often is referred to when discussing the efficacy of teachers is really two separate though highly intertwined constructs: teacher efficacy and teacher self-efficacy (Goddard et al., 2000). Teacher efficacy refers to a construct "purported to reveal the extent to which a teacher believes that the consequences of teaching - student motivation and learning - were in the hands of the teacher" (Tschannen-Moran et al., 1998, p. 205). Consequently, teacher selfefficacy refers to the individual's belief that, not only can the particular outcome be controlled, but that the individual teacher has the skills necessary to control it (Goddard et al., 2000). Additionally, teacher self-efficacy is subdivided into two constructs. The first is personal teacher self-efficacy, which is the individual feeling that he or she can bring about change in students. The second is general teacher self-efficacy, which is the belief that there are some external or uncontrollable factors that might affect this ability (Ross, 1992). As this study is focusing on the individual teacher and his or her selfperceptions about his or her teaching ability, the focus will remain on personal teacher self-efficacy, which I will refer to as simply teacher self-efficacy in this literature review. Because teacher self-efficacy refers to an individual's personal beliefs about their abilities, teacher self-efficacy is subject and environment specific (Dellinger, Bobbett, Olivier, \& Ellett, 2008). In fact, many have found that the effect of self-efficacy on the movement into action must be measured for each environment individually (Kranzler \& Pajares, 1997). This means that a teacher might feel quite comfortable teaching students how to add whole numbers and yet might feel less able to teach the same students how to add fractions. However, efficacious beliefs in one area can affect efficacious beliefs in 
other areas (Dellinger et al., 2008). For example, a teacher who feels confident in teaching fractions to a group of high-ability students might find increased confidence in teaching the same topic to a group of lower-ability students.

Measuring teacher self-efficacy. Teacher self-efficacy has been measured through a variety of different instruments. Earliest measurements of teacher self-efficacy were done through the RAND studies and measured both general and personal teacher self-efficacy (Tschannen et al. 1998). Problems existed with this instrument as the two self-efficacy measures were generally confused and combined through summation into a single measurement item (Dellinger et al., 2008). Recently, researchers have used a variety of other compound scales to measure underlying components of teacher selfefficacy, such as ability to motivate students, ability to impart knowledge, and ability to maintain classroom management (Dellinger et al., 2008). One of the most recent such instruments is the Self-Efficacy for Teaching Mathematics Instrument (SETMI), which measures two constructs of self-efficacy: pedagogy and teaching mathematics (McGee \& Wang, 2014).

Teacher mathematics self-concept. The second aspect of self-perceptions that is a focus for this study is mathematics self-concept, which is related to a teacher's mathematical knowledge. Mathematics self-concept is the view of one's own abilities that is formed through multiple experiences of competence as well as feedback received from others (Bong \& Skaalvik, 2003). Mathematical knowledge in teaching tends to be divided into two broad areas: mathematical content knowledge and mathematical pedagogical knowledge. Content knowledge refers to how well an individual can perform the skills required to complete various mathematical tasks (Hill, Rowan, \& Ball, 2005). 
This construct tends to be measured by standardized tests that may not always accurately measure a person's true knowledge in part because of measurement error or biased items (Hill et al., 2005). Alternately, mathematical pedagogical knowledge refers to how well a teacher knows the skills that are required to teach mathematics to students (Hill et al., 2005). Both content knowledge and pedagogical content knowledge have relationships with teacher self-concept and student academic achievement (Stevens et al. 2013). Particularly in mathematics, it has been found that there is a strong correlation between self-concept and actual achievement (Bong \& Skaalvik, 2003). Thus, I will also be exploring a teacher's mathematics self-concept because teachers who have stronger selfconcepts in mathematics are more likely to pass on those feelings to their students (Wood, 1998).

Where teacher self-concept refers to an individual's belief in their ability to teach, mathematics self-concept refers to "a teacher's own belief in his or her ability to perform mathematical tasks" (McGee \& Wang, 2014). This type of self-concept is influenced by a teacher's background knowledge (Kranzler \& Pajares, 1997) as well as the level of professional development support that a teacher receives in the classroom (Stevens et al., 2013).

Thus, I will be looking at the teacher's own self-efficacy in relation to mathematics. Some teachers feel self-efficacious when it comes to pedagogy, but they do not feel particularly effective when it comes to actually understanding mathematics on their own. This is problematic when teachers are asked to teach subjects that they do not feel comfortable with themselves (McGee \& Wang, 2014), which is of particular importance for teachers in the younger grades (e.g., elementary school). Many teachers of 
younger children do not have specialties in mathematics, and they also feel less selfefficacious in their own ability to do mathematics than do teachers at higher grades (Hudson, Henderson, \& Hudson, 2015).

\section{Conclusion}

This chapter presented a theoretical framework based on existing literature that situates the study presented in chapters 3-5. Through the course of the chapter, I have shown how students in the United States have fallen behind other students in developed nations on measures of mathematics achievement. With the understanding that mathematics education is important for our students for their future educational prospects, their future job prospects, and the future scientific development of our country, the fact that United States students perform at a below-average level is disturbing.

One way in which to continue the work to recuperate some of the achievement losses that we have seen is to find ways to increase academic engagement, ultimately with the goal of increasing student motivation. By helping our young elementary students to increase their emotional and behavioral engagement, it is possible that we can begin to build strong mathematical programs in this country.

In order to increase academic engagement, teachers who are capable of understanding both mathematics and pedagogy are needed. Teachers, who are more selfefficacious, especially in the area of mathematics, tend to be teachers who are also good at teaching. This study will look at the relationship between teacher self-efficacy, mathematics self-concept, and academic engagement in elementary school mathematics students. The study will focus on middle elementary students (grades 3, 4, and 5) because 
these students are still in a malleable stage of engagement development and yet can offer reliable answers to the study surveys. 


\section{CHAPTER III METHODOLOGY}

The purpose of this quantitative research study was to further explore the interrelationships among the variables of teacher self-efficacy, teacher mathematics selfconcept, and student behavioral and emotional engagement as well as potential moderators of those relationships. Specific research questions explored in this study were:

1. What is the relationship between teacher self-efficacy and teacher mathematics self-concept and student emotional and behavioral academic engagement?

2. Does the relationship between teacher self-efficacy and teacher mathematics selfconcept and student academic engagement differ for boys and girls?

3. Does the relationship between teacher self-efficacy and teacher mathematics selfconcept and student academic engagement differ for students who are identified as academically high achieving?

The remainder of this section describes the participants, measures, and analysis methods used in answering these questions.

\section{Participants}

Before beginning to recruit participants for the study, I needed to determine the number of participants that would be needed for the study. To determine the necessary 
sample size for this study, I considered several power analyses and rules of thumb.

Unfortunately, because this study is interested in the relationships of continuous measures with the outcome as well as the interaction of continuous measures with level-1 slopes, there is no closed-form solution for estimating power.

I first used power analysis software that is available for multi-level models, including both Optimal Design (Raudenbush et al., 2011) and PowerUp! (Dong, Maynard, \& Hofer, 2011) to estimate the necessary sample size to detect an effect size for a binary treatment variable. I used an alpha level of .05 and power level of .80, which is common for social sciences research (Cohen, 1990). Though I had not recruited specific schools, I was able to use school and district websites to make approximations of the number of students per class, thus I used 20 as a reasonable estimate of cluster size. Though there is not a great deal of research on the relationship between teacher selfefficacy and academic engagement, Lange (2010) found that there is a significant correlation of .833 between the two variables with elementary school children. I was able to use this value to calculate an approximate effect size of Cohen's $d=3.1$. Finally, I needed an estimate of the intraclass correlation (ICC) for the outcomes on the student measure. Using previously obtained data on the outcome measures from students in $1^{\text {st }}$ through $5^{\text {th }}$ grades, I calculated ICC's ranging from .013 for behavioral engagement to .13 for emotional engagement. Using the larger of the two ICC's in the power analysis, Optimal Design suggested the use of zero clusters and PowerUp! suggested the use of 5 clusters.

Next, I took into account common rules of thumb. Maxwell (2010) recommends at least 10 people per predictor for multiple regression. Because my independent 
variables of primary interest are at the teacher level, I applied this rule of thumb to the number of teachers needed in this study. I have two teacher control variables and four teacher independent variables, resulting in six total teacher predictors. Therefore, the rule of thumb indicates I need a minimum of 60 teachers in this study.

Based on these results, I chose to attempt to recruit the greatest required sample size of 60 clusters. As a final step, I used this information to estimate the power in a single-level multiple regression model using G*Power v.3.1.9.2 (Faul \& Erdfelder, 2007). Using a 2-tailed test, total sample size of 60,5 predictors, observed $R^{2}$ of 69 $\left(.833^{2}\right)$, we would have more than adequate power, with power equaling greater than .99 . I recruited schools from three different Midwest cities by sending invitation letters to principals in 20 schools. Principals who responded with interest were then sent teacher invitation letters to seek participation from teachers. Many schools responded with interest in the study and, ultimately, teachers from 12 schools agreed to participate. Of these schools, three were public schools from a large, urban district, one was a public school in a rural area, one was a parochial school situated in an urban area, and the final seven schools were parochial schools from the same school district but spread across rural and suburban areas.

Within the 12 participating schools, 55 teachers agreed to participate, though three of those teachers only gave the surveys to their students and did not complete their own surveys. Because some of the participating teachers taught mathematics to more than one group of students, my final sample included 63 distinct classes. From these classes, I received data from 1,112 students. 
I collected the following demographic data about students: gender, ethnicity, grade level, and high achievement status. These data were collected from teachers to increase the validity of the data. For the purpose of this study, "high achieving" students are defined as those students who have scored in $90^{\text {th }}$ percentile or above on the Terra Nova (given to students in the parochial schools) or similar standardized measure for the public school students. Student demographics are shown below in Table 1.

In looking at the data from the students, I found that several students were missing data on their gender, ethnicity, or achievement status. Additionally, three teachers did not provide their own demographic information. The analytic sample was created by removing those students for whom I did not have complete demographic information. Table 1 shows demographic data for all students who returned the survey as well as those students who were included in the analyses (i.e., had full student and teacher demographic data). 
Table 1

Student-level Demographic Data

\begin{tabular}{|c|c|c|}
\hline Factor & $\begin{array}{c}\text { Full sample } \\
n=1,112\end{array}$ & $\begin{array}{c}\text { Analytic sample: } \\
n=973\end{array}$ \\
\hline \multicolumn{3}{|l|}{ Gender } \\
\hline Boy & $567(51.0 \%)$ & $521(53.5 \%)$ \\
\hline Girl & $512(47.0 \%)$ & $452(46.5 \%)$ \\
\hline \multicolumn{3}{|l|}{ Ethnicity } \\
\hline White & $894(80.4 \%)$ & $817(84.0 \%)$ \\
\hline Asian/Pacific Islander & $27(2.4 \%)$ & $25(2.6 \%)$ \\
\hline Black & $121(10.9 \%)$ & $100(10.3 \%)$ \\
\hline Hispanic & $30(2.7 \%)$ & $25(2.6 \%)$ \\
\hline Mixed & $3(0.3 \%)$ & $3(0.3 \%)$ \\
\hline Other & $4(0.4 \%)$ & $3(0.3 \%)$ \\
\hline \multicolumn{3}{|l|}{ Grade } \\
\hline $3^{\text {rd }}$ Grade & $437(39.3 \%)$ & $361(37.1 \%)$ \\
\hline $4^{\text {th }}$ Grade & $348(31.3 \%)$ & $328(33.7 \%)$ \\
\hline $5^{\text {th }}$ Grade & $327(29.4 \%)$ & $284(29.2 \%)$ \\
\hline \multicolumn{3}{|l|}{ High Achievement Status } \\
\hline High Achieving & $75(6.7 \%)$ & $70(7.2 \%)$ \\
\hline Not High Achieving & $948(85.3 \%)$ & $903(92.8 \%)$ \\
\hline
\end{tabular}

From the teachers in this study, I collected demographic information and data on teacher self-efficacy and mathematics self-concept. I used a survey to collect the following demographic information: gender, number of years teaching, ethnicity, and mathematics background (do they have a major, minor, or emphasis in mathematics at the undergraduate or graduate level). As noted, three teachers did not complete the teacher information, thus I removed them (and their students) from the sample. Teacher and class demographics from the remaining teachers are shown below in Table 2. 
Table 2

Teacher and Class-level Demographic Data

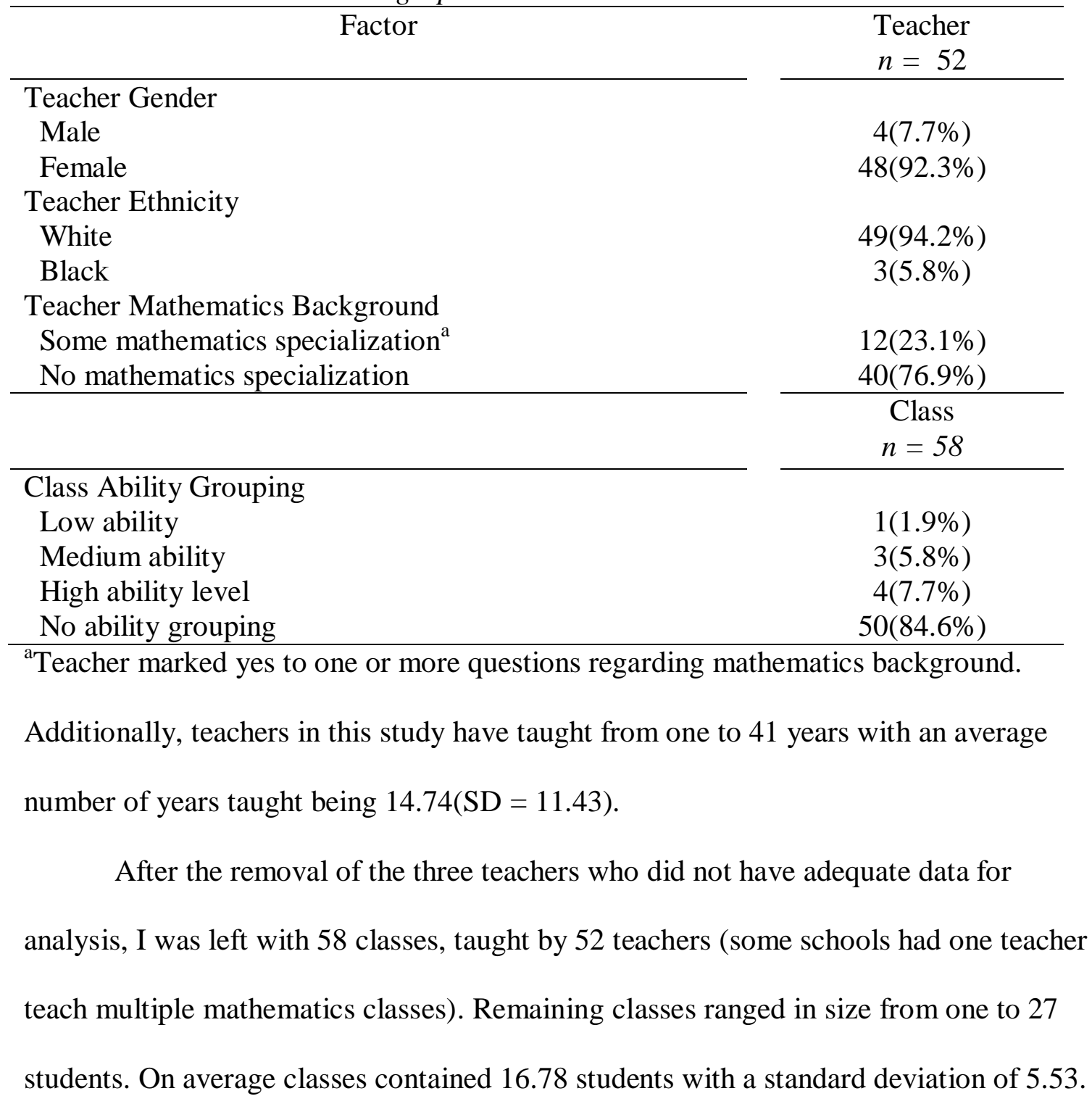

\section{Instrumentation}

\section{Students}

For the students, there was one outcome of interest: student academic engagement in mathematics. In order to measure this variable, students completed one instrument, the STEM Engagement Scale - Mathematics (SES-M). 
STEM Engagement Scale - Mathematics (SES-M). The SES (Cash \& Adelson, 2015) measures two components of academic engagement (behavioral and emotional) in science, engineering, and mathematics. For this study, only the mathematics scale was used. The SES-M presents students with 15 items measured on a five-point Likert-scale.

Of those 15 items, six measure emotional engagement through statements like "I wish my math class lasted longer," and nine measure behavioral engagement with items like "I volunteer to participate during math class." Items for each construct are averaged to obtain a subscale score. The SES-M has undergone content validation from experts in the field of engagement and motivation research, and Cash, Adelson, and Robinson (2016) conducted exploratory and confirmatory factor analyses on data from students in first through fifth grades to test the factor structure of the scales. Scores from this study's sample yielded the following internal consistency reliabilities: behavioral $\alpha=.77$ emotional $\alpha=.89$.

\section{Teachers}

Each teacher also completed two established instruments, the Self-Efficacy for Teaching Mathematics Instrument and the Self-Description Q.

Self-Efficacy for Teaching Mathematics Instrument (SETMI). Teacher selfefficacy was measured using the SETMI (McGee \& Wang, 2014). This instrument measures two components of teacher self-efficacy: pedagogy in mathematics (EPM) and teaching mathematics content (ETMC). The seven pedagogy items focus on the teacher's self-efficacy in teaching skills. Some items used to measure pedagogy of mathematics include "How well can you teach students to find area and perimeter?" and "How well can you implement alternative teaching strategies for mathematics in your classroom?" 
Alternately, the 15-item teaching mathematics subscale focuses on mathematics-specific items like "How well can you teach students to convert a fraction to a decimal?" All 22 items are measured on a 5-point Likert scale, and items are averaged to obtain subscale scores. Internal consistency for these two scales in this particular sample was calculated using Cronbach's alpha. For the pedagogy scale, $\alpha=.86$ and for the teaching mathematics content scale $\alpha=.93$, both indicators of good reliability in this sample.

The Self Description Questionnaire III - Mathematics (SDQ III-M). The SDQ III-M (Marsh \& O’Niell, 1984) was used to measure teachers' mathematics self-concept. The SDQ III-M has 10 items rated on an 8-point Likert scale, and the items are averaged to obtain a scale score. Items include statements like "I am quite good at mathematics" and "I have hesitated to take courses that involve mathematics." The SDQ III-M was designed for use with late adolescents (Marsh \& O’Neill, 1984) but has been used for study with high-ability college students (Rinn \& Cunningham, 2008), thus use with other adults does not seem to be inappropriate. On calculating the reliability of the SDQ III-M for the sample of teachers in this study, Cronbach's alpha was .93, indicating good internal consistency for this scale in this sample.

\section{Data Collection Procedures}

Data collection instruments were sent to the school principals for administration. Each principal received packets for individual teachers containing the necessary instruments. Teachers were asked to administer the SES-M to their students, reading the items aloud when necessary, based on student ability. Teachers were asked to complete the teacher instruments on their own. Principals then collected the scales from the teachers and made them available for my collection. 
Data on high achievement status were collected from the teacher. Each class was assigned a unique series of numbers. The teacher then assigned each student one number from that series. Using only the number as identification, the teacher completed a roster that gave the achievement status as well as demographic information (i.e., gender and ethnicity) of students in his/her class. Students then completed the survey linked to their assigned number. In this way, achievement status could be collected in a way that allowed all students to remain anonymous.

\section{Missing Data}

Of the 1,112 students completing the SES-M, 335 of them (30\%) were missing data on one or more of the instrument's indicators. Of those with missing data, 225 of them attended one of the two schools that were given an incomplete version of the SESM. This version was copied such that the final question was not visible to students. In total, $2.2 \%$ of the student outcome data were missing (this equates to 373 missing data points out of 16,680 data points requested). Of the other students who had one or more pieces of missing data, a look at the frequency of missingness revealed that boys and girls were equally likely to be missing data. In looking at the ethnicities, grades, and achievement status of students with missing data, these were roughly equivalent to the ethnicity, grade, and achievement status proportions in the total sample. These data appear to be missing at random and their missingness does not appear to be related to any of the variables of interest. For teachers, less than $1 \%$ of the requested outcome data were missing.

Missing data of non-demographic data were handled through the use of multiple imputation. Multiple imputation is preferred over listwise deletion or single imputation 
for handling missing data (McKnight, McKnight, Sidani, \& Figueredo, 2007). This method uses the observed data - both those from the individual with a missing data point and from other individuals - to create multiple imputed values for the missing data. These imputations are then stored in separate datasets that can be used for the statistical analyses (McKnight et al., 2007). For this study, 10 multiple imputation data sets were created using Mplus (Muthén \& Muthén , 1998-2010).

\section{Data Analysis}

Because the data violated the independence assumption inherent in most statistical techniques (i.e., students nested in classrooms), I used a two-level hierarchical linear model (HLM). When dealing with clustered data, HLM offers many advantages over other statistical techniques. HLM analyses produce standard errors that can account for the clustering of data, and HLM also presents researchers the ability to look at relationships and interactions across multiple levels of the hierarchical arrangement of the data (McCoach \& Adelson, 2010). I conducted independent but parallel analyses for each outcome, behavioral engagement and emotional engagement. Models were analyzed using the full version of HLM 7 (Raudenbush, Bryk, \& Congdon, 2013).

\section{HLM Model Building}

I used a model-building sequence recommended by Raudenbush \& Bryk (2002) for building the HLM models, conducting separate analyses for each of the two engagement outcomes. For each outcome, I began by creating the null model. This allowed me to calculate the intraclass correlation (ICC), which indicates the proportion of variability in engagement that existed between classes. Next, I built the control models, beginning with the student level and then the teacher level. Table 3 shows a list of all 
variables included in the analyses. After adding the student control variables (i.e., gender, ethnicity, and grade level), I checked the random variance for the slopes of the variables. Any slopes that did not have a significant level of random variance were fixed to be equal across students. After finalizing the level-1 model, I added the control variables at level 2 (the teacher level), predicting only the intercept. These variables were number of years teaching, mathematics background, gender, and ethnicity. As this study included a gifted education component, the standard coding for underrepresented minorities in gifted programs was used to create the code for ethnicity. Students who were black or Hispanic, those groups that tend to be underrepresented in programming, were grouped together and other students (i.e. whites and Asians) were placed in the other group. The base equations that were used for all subsequent analyses were as follows:

\section{Level-1 Model}

Math Engagement $\mathrm{ij}_{\mathrm{j}}=\beta_{0}+\beta_{1}($ Student Gender $)+\beta_{2}($ High Achieving

Status $)+\beta_{3}($ Student Ethnicity $)+r_{i j}$

\section{Level-2 Model}

$$
\begin{aligned}
& \left.\beta_{0}=\gamma_{00}+\gamma_{01} \text { (Years }\right)+\gamma_{02}(\text { Math Background })+\gamma_{03}(\text { Grade })+\mathrm{u}_{0} \\
& \beta_{1}=\gamma_{10}+\mathrm{u}_{1} \\
& \beta_{2}=\gamma_{20}+\mathrm{u}_{2} \\
& \beta_{3}=\gamma_{30}+\mathrm{u}_{3} \\
& \beta_{4}=\gamma_{40}+\mathrm{u}_{4}
\end{aligned}
$$


Table 3

Variables for Analysis

\begin{tabular}{|c|c|c|c|}
\hline Level & Variable & Coding & Type of variable \\
\hline \multirow[t]{7}{*}{ Student } & & & \\
\hline & Ethnicity & $\begin{array}{c}0=\text { White/Asian } \\
1=\text { Underrepresented } \\
\text { Minority }^{1}\end{array}$ & Control \\
\hline & $\begin{array}{c}\text { High Achievement } \\
\text { Status }\end{array}$ & $\begin{array}{c}0=\text { Non-high } \\
\text { achieving }\end{array}$ & $\begin{array}{l}\text { Independent } \\
\text { variable }\end{array}$ \\
\hline & & $1=$ High achieving & \\
\hline & Gender & $\begin{array}{c}0=\text { Male } \\
1=\text { Female }\end{array}$ & $\begin{array}{l}\text { Independent } \\
\text { variable }\end{array}$ \\
\hline & Emotional Engagement & Grand-mean centered & Outcome variable \\
\hline & Behavioral Engagement & Grand-mean centered & Outcome Variable \\
\hline \multirow[t]{7}{*}{ Teacher/Class } & & & \\
\hline & Math Background & $\begin{array}{c}0=\text { No math } \\
\text { specialization } \\
1=\text { Some math } \\
\text { specialization }\end{array}$ & Control \\
\hline & Grade & Centered at $3^{\text {rd }}$ grade & Control \\
\hline & Years & Grand-mean centered & Control \\
\hline & $\begin{array}{c}\text { Self-efficacy: Pedagogy } \\
\text { of Mathematics } \\
\text { (Pedagogy) }\end{array}$ & Grand-mean centered & $\begin{array}{c}\text { Independent } \\
\text { variable }\end{array}$ \\
\hline & $\begin{array}{l}\text { Self-efficacy: Teaching } \\
\text { Mathematics (Concepts) }\end{array}$ & Grand-mean centered & $\begin{array}{c}\text { Independent } \\
\text { variable }\end{array}$ \\
\hline & $\begin{array}{l}\text { Mathematics self- } \\
\text { concept (Self-Concept) }\end{array}$ & Grand-mean centered & $\begin{array}{l}\text { Independent } \\
\text { variable }\end{array}$ \\
\hline
\end{tabular}

${ }^{1}$ This group includes students who are black, Hispanic, or of mixed descent 


\section{Research Question 1}

To answer research the first question, "What is the relationship between two aspects of teacher self-efficacy and student emotional and behavioral academic engagement?", I added three variables as predictors of the intercept: teacher self-efficacy in pedagogy of mathematics (Pedagogy), teacher self-efficacy in teaching mathematics concepts (Content), and teacher self-concept in mathematics (Self-Concept). All equations remain the same as the control equations shown above with the exception of the equation for the intercept, which is shown below:

$$
\begin{aligned}
& \beta_{0}=\gamma_{00}+\gamma_{01}(\text { Experience })+\gamma_{02}(\text { Math_Background })+\gamma_{03}(\text { Grade })+\gamma_{04} \\
& (\text { Self-Concept })+\gamma_{05}(\text { Pedagogy })+\gamma_{06}(\text { Content })+u_{0}
\end{aligned}
$$

I examined the significance levels of the fixed effects for Self-Concept, Pedagogy, and Content. Finally, I calculated the proportion of between-group variance explained by self-concept, pedagogy, and concepts above and beyond the control variables by comparing this model between-group variability in the intercept between this model and the control model.

\section{Research Question 2}

To answer the second question, "Does the relationship between teacher selfefficacy and teacher mathematics self-concept and student academic engagement differ for boys and girls?" I added the teacher-level independent variables as predictors of the student gender slope and then calculated the proportion of variance explained in the gender slope by the addition of these variables. For this model, all equations remained the same as stated in the control model except for the equation modeling the gender slope, which now was as follows: 


$$
\begin{aligned}
& \mathrm{B}_{2}=\gamma_{20}+\gamma_{23}(\text { SELF-CONCEPT })+\gamma_{24}(\text { PEDAGOGY })+\gamma_{25} \\
& (\text { CONCEPTS })+u_{2}
\end{aligned}
$$

As in research question 1 , I examined the significance of the fixed effects for selfconcept, pedagogy, and concepts. Finally, I calculated the proportion of variance explained in the gender slope by comparing the between-group variability in that slope in the control model and in this model.

\section{Research Question 3}

To answer the third question, "Does the relationship between teacher self-efficacy and teacher mathematics self-concept and student academic engagement differ for students who are identified as academically high achieving?," I added the three teacherlevel variables of interest as predictors to the ability slope. For this model, all equations remained the same as stated in the control model except for the equation modeling the ability slope shown below:

$$
\begin{aligned}
& \mathrm{B}_{3}=\gamma_{30}+\gamma_{33}(\text { SELF-CONCEPT })+\gamma_{34}(\text { PEDAGOGY })+\gamma_{35} \\
& (\text { CONCEPTS })+u_{4}
\end{aligned}
$$

As above, I looked at the significance of the fixed effect to examine whether these variables had different effects for high-achieving and non-high-achieving students. I then calculated the proportion of variance explained in the ability slope after adding the teacher variables of interested. This analysis allowed me to explore the differing relationship among the independent variables on student engagement for students of different academic achievement levels. 


\section{Conclusion}

Through the use of carefully constructed hierarchical linear models, I was able to explore the relationships between teacher self-efficacy and self-concept and student academic engagement while controlling for a number of both teacher and student characteristics. Additionally, I was able to identify whether significant differences in these relationships exist between key groups of students, most notably, those of different genders, and different abilities. The HLM process allowed me to look at the proportion of variance explained by the variables added into my models to provide a better understanding of how teacher characteristics relate to the engagement of students in classrooms. 


\section{CHAPTER IV}

\section{RESULTS}

This chapter will detail the analysis and results of this study. Data were analyzed using HLM version 7.01 using full maximum likelihood estimation. HLM uses each of the 10 imputed datasets and creates a pooled result for analysis. Because each research questions involves two outcomes (behavioral engagement and emotional engagement), analyses were run separately on each outcome. Each section of this chapter will report first on the behavioral engagement outcome and then on the emotional engagement outcome.

\section{Initial Analyses}

Before answering the research questions, I checked for normality and looked at the descriptive statistics for each of my outcome variables. I also looked at the reliability of the scores for each of the instruments to ensure that they were measuring well for the students in my sample.

\section{Normality}

Prior to conducting HLM analyses on the collected data, I examined the normality of the data. I did this through visual examination of the histogram and P-P plots for the two outcome variables because the two traditional tests for nonnormality (the ShapiroWilk test and the Kolmogorov-Smirnov test) are known to be unreliable with sample sizes over 300 (Kim, 2013) and my sample size was 973. The histograms appeared to be 
slightly peaked and showed some negative skew, which was indicative of some slight violation of the normality assumption. Figures 3 and 4 shows the histograms for the two outcome variables (behavioral and emotional engagement).

Figure 3. Histogram for Behavioral Engagement Outcome

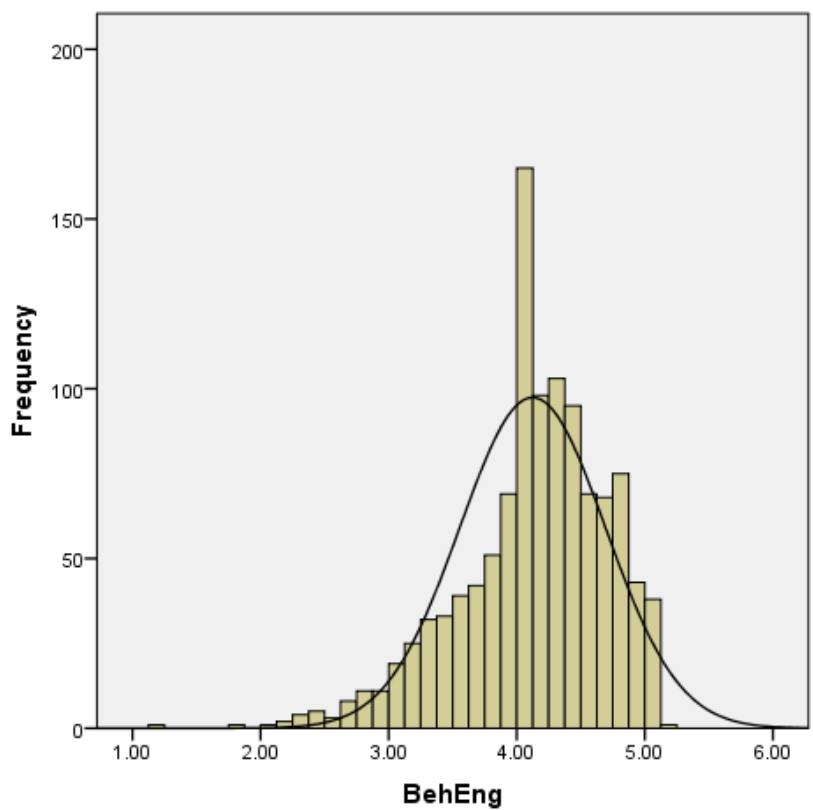

Figure 4. Histogram for Emotional Engagement Outcome

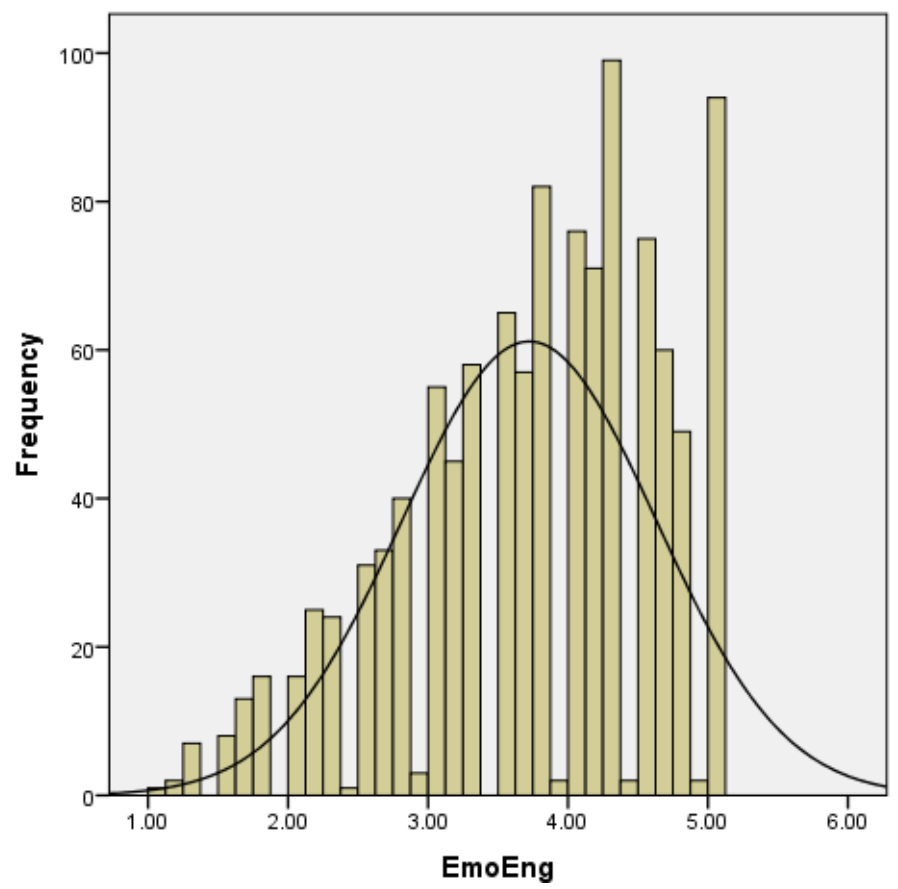


I also examined the P-P plots, which followed general 45-degree trajectories. Figures 5 and 6 show the P-P plots.

Figure 5. P-P Plot for Behavioral Engagement

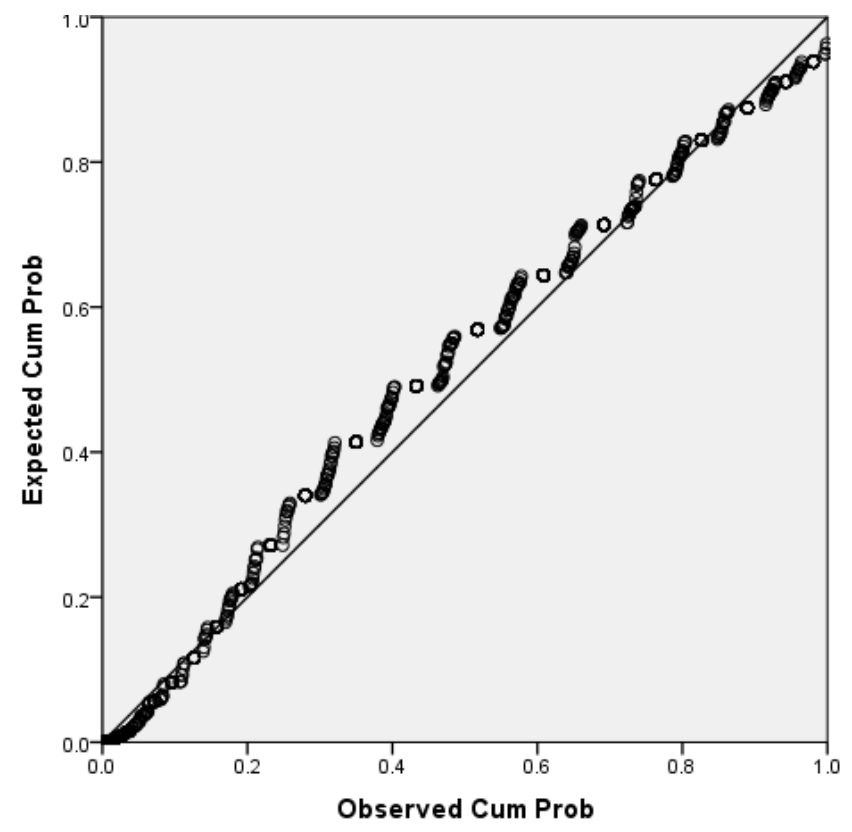

Figure 6. P-P Plot for Emotional Engagement

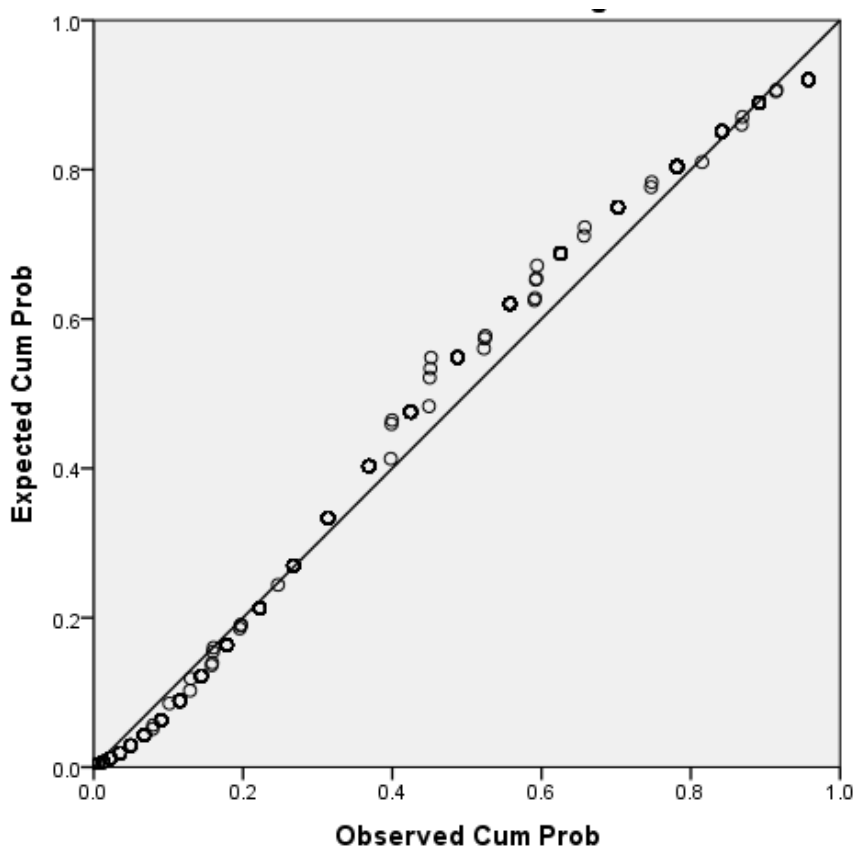


Finally, I compared the robust standard errors to the standard errors (both provided by the HLM software) and saw that the two sets of errors were very close. Thus, I chose to proceed with the data as they were and did not attempt a transformation.

\section{Descriptive Statistics}

Students. Using the SES-M item scores, I created mean scores for the two subscales of the instrument (behavioral and emotional engagement), separately for each of the 10 imputed datasets. To calculate the descriptive statistics for the two outcome variables, behavioral and emotional engagement (see Table 4), I found the mean and standard deviation for the mean scores for each of my ten imputed samples. I then found the mean and mean standard deviation for all ten samples.

Table 4

Descriptive Statistics for Student Outcomes [Mean(SD)]

\begin{tabular}{lccccc}
\hline & Full sample & Boys & Girls & $\begin{array}{c}\text { Not high } \\
\text { achieving }\end{array}$ & High achieving \\
\hline $\begin{array}{l}\text { Behavioral } \\
\begin{array}{l}\text { Engagement } \\
\text { Emotional }\end{array}\end{array}$ & 4.13(0.56) & $4.08(.59)$ & $4.19(0.53)$ & $4.13(0.56)$ & $4.27(0.43)$ \\
Engagement & & & & & \\
\hline
\end{tabular}

Note. These statistics are based on averages of the 10 multiple imputation datasets.

Next, I examined the internal consistency of the scale scores for the students in this sample. According to McCoach, Gable, and Madura (2013), reliability of at least .80 is preferred to indicate good internal consistency. For this sample, the pooled reliability for the behavioral engagement scale was $.79, \mathrm{CI}_{95}=[.78, .81]$ which is not statistically significantly below the level generally accepted as good reliability and is consistent with prior reliability estimates for this scale (Cash \& Adelson, 2015). Reliability for the emotional engagement was found to be $.88, \mathrm{CI}_{95}=[.87, .89]$. 
Teachers. I followed a similar procedure for calculating the descriptive statistics for the teacher data. I collected data to produce three teacher variables from two different instruments. I averaged the 10 items from the SDQ-III to calculate a scale score for teacher self-concept in mathematics (CM), seven items from the SETMI to calculate a scale score for efficacy for pedagogy in mathematics (EPM), and 15 items from the SETMI to determine a scale score for efficacy for teaching mathematics content (ETMC). Table 5 shows the descriptive for each teacher variable of interested.

Table 5

Descriptive Statistics for Teacher Outcomes

\begin{tabular}{llccc}
\hline Outcome & & Mean & & SD \\
\hline Self-concept in Mathematics (CM) $^{\mathrm{a}}$ & & 6.00 & 1.28 \\
Efficacy for Pedagogy in Mathematics (EPM) $^{\mathrm{b}}$ & & 4.03 & 0.56 \\
Efficacy for Teaching Mathematics Content (ETMC) $^{\mathrm{b}}$ & & 4.10 & 0.64 \\
\hline
\end{tabular}

Note. These statistics are based on averages of the ten multiple imputation datasets. ${ }^{a}$ The SDQ-III measures on a scale from $1-8$

${ }^{\mathrm{b}}$ The SETMI measures on a scale from $1-5$

I also calculated the reliability of these instruments with the sample for this study. This step was especially important given that much of the research on both instruments had been on students or pre-service teachers rather than in-service teachers. The pooled reliability for $\mathrm{CM}$ was.93, $\mathrm{CI}_{95}=[90, .95]$, for $\mathrm{EPM}$ was.85, $\mathrm{CI}_{95}=[.78, .90]$, and for ETMC was.93, $\mathrm{CI}_{95}=[.90, .94]$. All of these indicate good internal consistency of measurement for this sample.

\section{Model Building}

In order to answer the three research questions, I built a series of models. Below, I describe the model-building process: identifying first the null model to which the others are compared, then the control model that contains all of the control variables, and next the final models for each of the questions. 


\section{Unconditional Model}

I first estimated the models with an engagement score as the outcome and no predictors. These models allowed for the calculation of the intraclass correlation (ICC). The ICC for behavioral engagement was .0852. Thus, $8.52 \%$ of variability in behavioral engagement was between classes while $91.48 \%$ of the variability is between students within each class. For emotional engagement, the ICC was.1926, indicating that $19.26 \%$ of variability in emotional engagement lies between classes.

\section{Control Model}

Next, I built models using the student and teacher control variables. At the student level, gender, high achievement status, and ethnicity served as control variables. At the teacher level, there were three control variables: grade level of the class, teacher experience (measured by years of teaching), and teacher mathematics background. Though data on teacher gender and ethnicity were collected, they were not used in the final analysis as the sample of teachers was overwhelmingly female and white. Coding decisions for all variables can be found in Table 3 in Chapter 3.

The control models were estimated by entering all level-one variables while at first allowing all variances for those variables to randomly vary across classes and then by fixing nonsignificant variances, one at a time. For behavioral engagement, only the gender slope randomly varied across groups. For emotional engagement, only the intercept slope varied across groups. Final estimates for the two control models are shown in Tables 6 and 7. For all models, a predetermined alpha-level of .05 was used for all decisions on statistical significance. 
Table 6

Control Model for Behavioral Engagement

\begin{tabular}{|c|c|c|c|c|}
\hline Fixed effects & Coeffici & & $t(\mathrm{df})$ & $p$ \\
\hline \multicolumn{5}{|c|}{ Model for mean behavioral engagement $\left(\beta_{0}\right)$} \\
\hline Intercept $\left(\gamma_{00}\right)$ & \multicolumn{2}{|c|}{$4.10(.05)$} & $79.22(54)$ & $<.001$ \\
\hline Experience $\left(\gamma_{01}\right)$ & \multicolumn{2}{|c|}{$-0.002(.03)$} & $-0.69(54)$ & .494 \\
\hline MathBackground $\left(\gamma_{02}\right)$ & \multicolumn{2}{|c|}{$-0.08(.003)$} & $-1.24(54)$ & .221 \\
\hline $\operatorname{Grade}\left(\gamma_{03}\right)$ & \multicolumn{2}{|c|}{$-0.002(.07)$} & $-0.08(54)$ & .939 \\
\hline \multicolumn{5}{|l|}{ Model for Gender slope $\left(\beta_{1}\right)$} \\
\hline Intercept $\left(\gamma_{10}\right)$ & \multicolumn{2}{|c|}{$0.13(.04)$} & $3.26(57)$ & .002 \\
\hline \multicolumn{5}{|c|}{ Model for Achievement slope $\left(\beta_{2}\right)$} \\
\hline Intercept $\left(\gamma_{20}\right)$ & \multicolumn{2}{|c|}{$0.21(.07)$} & $3.823(855)$ & .003 \\
\hline \multicolumn{5}{|c|}{ Model for Ethnicity slope $\left(\beta_{3}\right)$} \\
\hline Intercept $\left(\gamma_{30}\right)$ & \multicolumn{2}{|c|}{$-0.12(.06)$} & $-2.10(855)$ & .036 \\
\hline Random Effects & Variance & $\overline{d f}$ & $\chi^{2}$ & $p$ \\
\hline Var. in class means $\left(\tau_{00}\right)$ & 0.038 & 52 & 121.72 & $<0.001$ \\
\hline Var. in Gender slope $\left(\tau_{11}\right)$ & 0.026 & 55 & 75.26 & .036 \\
\hline Var. within classes $\left(\sigma^{2}\right)$ & 0.265 & & & \\
\hline
\end{tabular}

Of the variables that were added to the model for behavioral engagement, none of the class-level predictors were statistically significant predictors of the intercept (average behavioral engagement). Despite their nonsignificance, they remained in the model as control variables. In this control model, all of the student-level predictors (gender, achievement status, ethnicity, and underrepresented minority status), were significant predictors of the intercept. Girls, high-achieving students, and nonminority students all indicated significantly higher levels of behavioral engagement than did boys, averageand low-achieving students, and those in underrepresented ethnic minority groups.

In this model, it can be seen that, after controlling for class- and student-level predictors, the intercept, average behavioral engagement, was $4.10\left(\gamma_{00}\right)$ and was statistically significant $(t[54]=79.22, p<.001)$, indicating that the mean behavioral engagement is not equal to zero. Additionally, the intercept variance component is 
statistically significant $\left(\chi^{2}[52]=121.72, p<.001\right)$, indicating that classes vary significantly on average behavioral engagement, with some classes having students indicating higher levels of behavioral engagement and some classrooms having students indicating lower levels of behavioral engagement. The only significant predictors of behavioral engagement are gender and high achievement status. The differential in mean behavioral engagement for girls is $0.13\left(\gamma_{10}\right)$, indicating that girls' behavioral engagement scores are 0.13 points higher than boys after controlling for all other variables. Similarly, students of high ability score 0.21 points $\left(\gamma_{20}\right)$ above their counterparts on behavioral engagement when all other variables are held constant.

\section{Table 7}

\section{Control Model for Emotional Engagement}

\begin{tabular}{|c|c|c|c|}
\hline Fixed effects & Coefficient(SE) & $t(\mathrm{df})$ & $p$ \\
\hline \multicolumn{4}{|c|}{ Model for mean behavioral engagement $\left(\beta_{0}\right)$} \\
\hline Intercept $\left(\gamma_{00}\right)$ & $3.70(.10)$ & $38.634(54)$ & $<.001$ \\
\hline Experience $\left(\gamma_{01}\right)$ & $-0.01(.01)$ & $-1.85(54)$ & .070 \\
\hline MathBackground $\left(\gamma_{02}\right)$ & $-0.03(.13)$ & $-0.201(54)$ & .841 \\
\hline $\operatorname{Grade}\left(\gamma_{03}\right)$ & $0.01(.07)$ & $0.095(54)$ & .924 \\
\hline \multicolumn{4}{|c|}{ Model for Gender slope $\left(\beta_{1}\right)$} \\
\hline Intercept $\left(\gamma_{10}\right)$ & $0.04(.05)$ & $0.612(912)$ & .496 \\
\hline \multicolumn{4}{|c|}{ Model for Achievement slope $\left(\beta_{2}\right)$} \\
\hline Intercept $\left(\gamma_{20}\right)$ & $0.25(.11)$ & 2.141(912) & .033 \\
\hline \multicolumn{4}{|c|}{ Model for Ethnicity slope $\left(\beta_{3}\right)$} \\
\hline Intercept $\left(\gamma_{30}\right)$ & $0.05(.09)$ & $0.515(912)$ & 607 \\
\hline Random Effects & Variance & $\chi^{2}$ & $p$ \\
\hline Var. in class means $\left(\tau_{00}\right)$ & 0.149 & 252.45 & $<.001$ \\
\hline Var. within classes $\left(\sigma^{2}\right)$ & 0.658 & & \\
\hline
\end{tabular}

Unlike with behavioral engagement, for emotional engagement only highachievement status is a statistically significant predictor of the intercept (average emotional engagement). Those students who are identified as high achieving indicate that they are more emotionally engaged than their non-high-achieving counterparts. 
As with behavioral engagement, both the intercept of $3.67(t[54]=38.63, p$ $<.001)$ and the intercept variance $\left(\chi^{2}[54]=252.45, p<.001\right)$ component were statistically significant. Thus, emotional engagement is statistically significantly different from zero, and it does vary across classes. After accounting for all other variables, mean emotional engagement for students in this study was 3.67 points. After controlling for all other variables, high achievement status remains a significant predictor of emotional engagement, as it did in the control model. Those students identified as high achieving score, on average, 0.25 points $\left(\gamma_{20}\right)$ higher on the measure of emotional engagement.

Using these control models as base models to which other models might be compared, I next estimated models to answer each of the three research questions.

\section{Research Question 1}

The first research question is about the relationship between teacher selfperceptions and student academic engagement. To answer this question, I added the three measures of teacher self-perceptions (mathematics self-concept, self-efficacy for pedagogy in mathematics, and self-efficacy for teaching mathematics content) as predictors of the intercept (average engagement).

Behavioral engagement. To answer Research Question 1 in relation to behavioral engagement (see Table 8), I examined the fixed effects for the three added teacher variables. Mathematics self-concept $\left(\gamma_{04}=.02, \mathrm{t}[51]=.746, p=.459\right)$, selfefficacy for mathematics pedagogy $\left(\gamma_{05}=.02, \mathrm{t}[51]=.350, p=.727\right)$, and self-efficacy for teaching mathematics content $\left(\gamma_{07}=.04, \mathrm{t}[51]=.735, p=.466\right)$ were not statistically significantly related to the intercept. Thus, it would seem that these variables are not related to students' mean behavioral engagement scores. To determine the extent to 
which the addition of the three teacher self-efficacy variables explains variability in behavioral engagement scores, I calculated the proportion of variance explained (PVE) in the intercept. This value is computed by subtracting the variability in the intercept for this model from the variability in the intercept from the control model and then dividing by the total original variability (i.e., the variability in the control). However, in this model, the variance in the intercept actually rose after the addition of the three teacher selfefficacy variables, meaning that the PVE could not be calculated and indicating that these three variables do not explain any of the remaining variance in the intercept after controlling for teacher and student characteristics.

Table 8

Contextual Model for Behavioral Engagement, Answering Research Question 1

\begin{tabular}{|c|c|c|c|c|}
\hline Fixed effects & \multicolumn{2}{|c|}{ Coefficient(SE) } & $t(\mathrm{df})$ & $p$ \\
\hline \multicolumn{5}{|c|}{ Model for mean behavioral engagement $\left(\beta_{0}\right)$} \\
\hline Intercept $\left(\gamma_{00}\right)$ & \multirow{2}{*}{\multicolumn{2}{|c|}{ 4.13(.05) }} & $76.16(51)$ & $<.001$ \\
\hline Experience $\left(\gamma_{01}\right)$ & \multirow{2}{*}{$-0.001(.003)$} & & $-0.434(51)$ & .666 \\
\hline MathBackground $\left(\gamma_{02}\right)$ & \multirow{2}{*}{\multicolumn{2}{|c|}{$\begin{array}{l}-0.14(.08) \\
-0.01(.04)\end{array}$}} & $-1.786(51)$ & .080 \\
\hline $\operatorname{Grade}\left(\gamma_{03}\right)$ & & & $-0.322(51)$ & .749 \\
\hline Self-concept $\left(\gamma_{04}\right)$ & \multicolumn{2}{|c|}{$0.02(.03)$} & $0.746(51)$ & 459 \\
\hline Pedagogy $\left(\gamma_{05}\right)$ & \multicolumn{2}{|c|}{$0.02(.06)$} & $0.350(51)$ & .727 \\
\hline Content $\left(\gamma_{06}\right)$ & \multicolumn{2}{|c|}{$0.04(.06)$} & $0.735(51)$ & .466 \\
\hline Model for Gender slope $(\beta$ & \multirow{2}{*}{\multicolumn{2}{|c|}{$0.13(.04)$}} & & \\
\hline Intercept $\left(\gamma_{10}\right)$ & & & $3.206(57)$ & .002 \\
\hline $\begin{array}{l}\text { Model for Achievement sl } \\
\text { Intercept }\left(\gamma_{20}\right)\end{array}$ & \multicolumn{2}{|c|}{$0.23(.07)$} & $3.13(57)$ & .002 \\
\hline $\begin{array}{l}\text { Model for Ethnicity slope } \\
\text { Intercept }\left(\gamma_{30}\right)\end{array}$ & \multicolumn{2}{|c|}{$-0.11(.06)$} & $-1.933(855)$ & .054 \\
\hline Random Effects & Variance & df & $\chi^{2}$ & $p$ \\
\hline Var. in class means $\left(\tau_{00}\right)$ & 0.045 & 49 & 130.17 & $<.001$ \\
\hline Var. in Gender slope $\left(\tau_{11}\right)$ & 0.026 & 55 & 75.39 & .035 \\
\hline Var. within classes $\left(\sigma^{2}\right)$ & 0.265 & & & \\
\hline
\end{tabular}

Emotional engagement. As I did in the behavioral engagement model above, I examined the fixed effects for the three variables that were added to the equation (see 
Table 9). Mathematics self-concept $\left(\gamma_{04}=-.10, \mathrm{t}[51]=-1.62, p=.112\right)$, self-efficacy for mathematics pedagogy $\left(\gamma_{05}=.12, \mathrm{t}[51]=.99 p=.327\right)$, and self-efficacy for teaching mathematics content $\left(\gamma_{07}=.15, \mathrm{t}[51]=1.38, p=.175\right)$ were not statistically significantly related to the intercept. As before, none of the teacher self-perceptions variables were statistically significantly related to emotional engagement scores. However, unlike for behavioral engagement, emotional engagement variability did drop as a result of the addition of the three teacher self-efficacy variables. The PVE in the intercept was 0.034 . Thus, about $3.4 \%$ of the variability in class means is explained by teacher mathematics self-concept, self-efficacy for pedagogy of mathematics, and selfefficacy for teaching mathematics concepts above and beyond the control variables. Interestingly, teacher experience did became a statistically significant predictor of students' emotional engagement $\left(\gamma_{01}=-.01, t[51]=-2.09, p=.041\right)$ when teacher selfperceptions were controlled for. For each one year of experience that a teacher has above the mean experience (14.41 years), students in that class are expected to score 0.01 points less on emotional engagement. 
Table 9

Contextual Model for Emotional Engagement, Answering Research Question 1

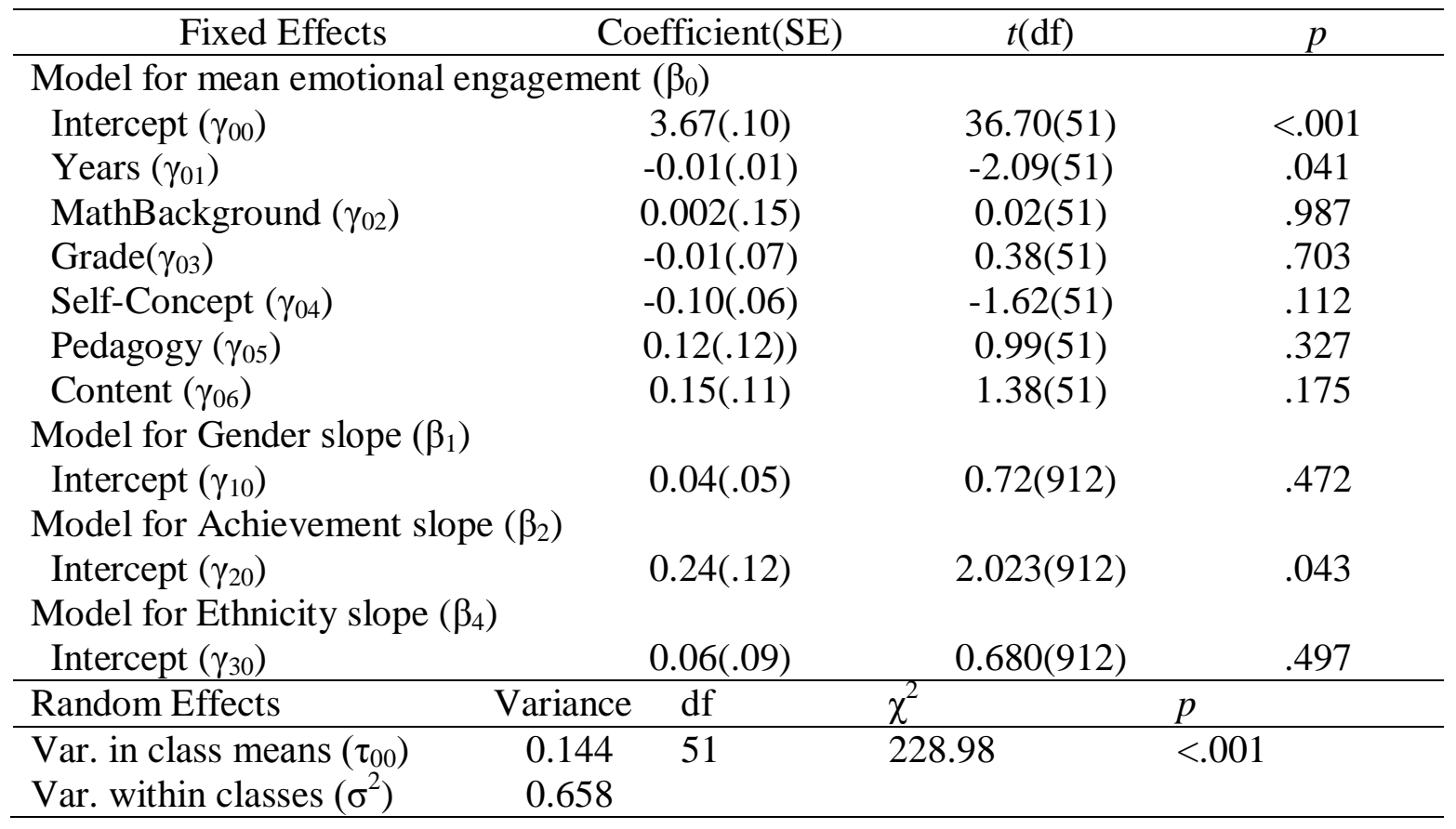

Summary of Research Question 1 results. Research Question1 asked about the relationship between teacher mathematics self-perceptions (specifically, teacher mathematics self-concept, self-efficacy in pedagogy of mathematics, and self-efficacy in teaching mathematics content) and student academic engagement. As described in the results above, there was no relationship between the three teacher self-perceptions measures and student academic engagement. The teacher self-perceptions did not explain any of the variability between classes in behavioral engagement, although it did explain $3.4 \%$ of the variability between classes in emotional engagement. 


\section{Research Question 2}

Next, the three teacher variables of mathematics self-concept, self-efficacy in mathematics pedagogy, and self-efficacy for teaching mathematics content were added to the gender slope to see if they moderated the differences between boys and girls.

Behavioral engagement. In this model (see Table 10), teacher mathematics selfconcept $\left(\gamma_{11}=-.07, t[54]=-2.14, p=.037\right)$ and self-efficacy for teaching mathematics content $\left(\gamma_{13}=.22, t[54]=3.24, p=.002\right)$ were both statistically significant predictors of the differences between males and females in behavioral engagement, though selfefficacy for mathematics pedagogy $\left(\gamma_{12}=.07, t[54]=0.95, p=<.349\right)$ was not. Girls, who are already predicted to score high on the measure of behavioral engagement $\left(\gamma_{10}=\right.$ $.13, t[54]=3.60, p<.001)$, in a class with a teacher who scored one point above the mean on self-efficacy for teaching mathematics content were expected to score an additional 0.22 points higher $\left(\gamma_{13}, t[54]=3.24, p=.002\right)$ on the measure of behavioral engagement. Inversely, girls in a class with a teacher who scored a point higher on the measure of mathematics self-concept were expected to have their differential from boys in behavioral engagement decrease by 0.07 points $\left(\gamma_{13}, t[54]=-2.14, p=.037\right)$. Figure 3 shows predicted values for girls and boys in classes with different teacher characteristics to illustrate this relationship. These predicted values represented what would be expected from a third-grade student who is neither a minority nor high achieving and whose teacher was at the average for all control variables. 
Table 10

Contextual Model for Behavioral Engagement by Gender, Answering Research Question 2

\begin{tabular}{|c|c|c|c|}
\hline Fixed effects & Coefficient(SE) & $t(\mathrm{df})$ & $p$ \\
\hline \multicolumn{4}{|c|}{ Model for mean behavioral engagement $\left(\beta_{0}\right)$} \\
\hline Intercept $\left(\gamma_{00}\right)$ & $4.13(.05)$ & $77.81(51)$ & $<.001$ \\
\hline Years $\left(\gamma_{01}\right)$ & $-0.001(.003)$ & $-0.38(51)$ & .705 \\
\hline MathBackground $\left(\gamma_{02}\right)$ & $-0.13(.08)$ & $-1.73(51)$ & .090 \\
\hline Grade $\left(\gamma_{03}\right)$ & $-0.01(.04)$ & $-0.38(51)$ & .716 \\
\hline Self-Concept $\left(\gamma_{04}\right)$ & $0.06(.04)$ & $1.76(51)$ & .084 \\
\hline Pedagogy $\left(\gamma_{05}\right)$ & $0.07(.07)$ & $0.945(51)$ & .349 \\
\hline Content $\left(\gamma_{06}\right)$ & $-0.09(.07)$ & $-1.294(51)$ & .201 \\
\hline \multicolumn{4}{|l|}{ Model for Gender slope $\left(\beta_{1}\right)$} \\
\hline Intercept $\left(\gamma_{10}\right)$ & $0.13(.04)$ & $3.60(54)$ & $<.001$ \\
\hline Self-Concept $\left(\gamma_{11}\right)$ & $-0.07(.04)$ & $-2.14(54)$ & .037 \\
\hline $\operatorname{Pedagogy}\left(\gamma_{12}\right)$ & $0.07(.07)$ & $0.95(54)$ & .349 \\
\hline $\operatorname{Content}\left(\gamma_{13}\right)$ & $0.22(.07)$ & $3.24(54)$ & .002 \\
\hline \multicolumn{4}{|c|}{ Model for Achievement slope $\left(\beta_{2}\right)$} \\
\hline Intercept $\left(\gamma_{20}\right)$ & $0.23(.06)$ & $3.116(855)$ & .002 \\
\hline \multicolumn{4}{|c|}{ Model for Ethnicity slope $\left(\beta_{3}\right)$} \\
\hline Intercept $\left(\gamma_{30}\right)$ & $-0.12(.06)$ & $-2.108(855)$ & .035 \\
\hline Random Effects & Variance $\mathrm{df}$ & $\chi^{2}$ & $p$ \\
\hline Var. in class means $\left(\tau_{00}\right)$ & 0.039 & 116.94 & $<.001$ \\
\hline Var. in Gender slope $\left(\tau_{11}\right)$ & 0.010 & 57.62 & .275 \\
\hline Var. within classes $\left(\sigma^{2}\right)$ & 0.265 & & \\
\hline
\end{tabular}

Figure 7

\section{Predicted Values for Behavioral Engagement}

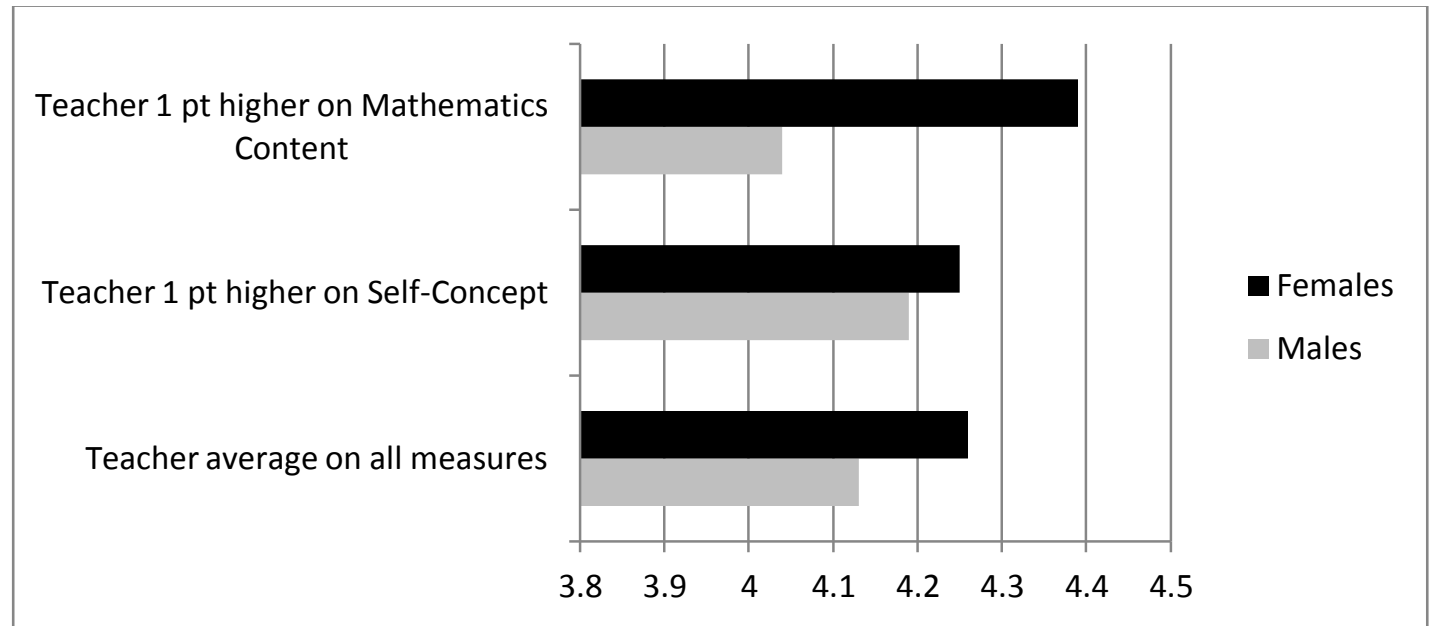


After examining the fixed effects for the teacher self-perceptions variables added as predictors to the gender slope, I calculated the proportion of variance in this slope explained by these variables. Without the three teacher variables of interest, variance in the gender slope was 0.026. After accounting for all three measures of teacher selfperceptions, the variance in the gender slope dropped to 0.010 . Thus, $61.5 \%$ of the variance in the gender slope can be explained by the linear combination of teacher mathematics self-concept, self-efficacy for mathematics pedagogy, and self-efficacy for teaching mathematics content.

Emotional engagement. Unlike for behavioral engagement, none of the measures of teacher self-perceptions significantly moderated the gender slope or emotional engagement (see Table 11). Mathematics self-concept $\left(\gamma_{11}=-.06, t[909]=-1.16, p=\right.$ $.051)$, self-efficacy for mathematics pedagogy $\left(\gamma_{12}=22, t[909]=1.96, p=.051\right)$, and self-efficacy for teaching mathematics content $\left(\gamma_{13}=.19, t[909]=1.91, p=.057\right)$ do not significantly relate to the gender differential in emotional engagement. This was expected as the gender slope did not statistically significantly vary between classes. 
Table 11

Contextual Model for Emotional Engagement by Gender, Answering Research Question 2

\begin{tabular}{|c|c|c|c|c|}
\hline Fixed effects & & Coefficient(SE) & $t(\mathrm{df})$ & $p$ \\
\hline \multicolumn{5}{|c|}{ Model for mean emotional engagement $\left(\beta_{0}\right)$} \\
\hline Intercept $\left(\gamma_{00}\right)$ & & $3.67(.10)$ & $36.86(51)$ & $<.001$ \\
\hline Years $\left(\gamma_{01}\right)$ & & $-0.01(.07)$ & $-2.02(51)$ & .049 \\
\hline MathBackground $\left(\gamma_{02}\right)$ & & $0.01(.15)$ & $0.04(51)$ & .967 \\
\hline Grade $\left(\gamma_{03}\right)$ & & $0.03(.07)$ & $0.339(51)$ & .736 \\
\hline Self-Concept $\left(\gamma_{04}\right)$ & & $-0.07(.05)$ & $-1.11(51)$ & .274 \\
\hline Pedagogy $\left(\gamma_{05}\right)$ & & $0.02(.11)$ & $0.147(51)$ & .884 \\
\hline Content $\left(\gamma_{06}\right)$ & & $0.06(.10)$ & $0.468(51)$ & .642 \\
\hline \multicolumn{5}{|c|}{ Model for Gender slope $\left(\beta_{1}\right)$} \\
\hline Intercept $\left(\gamma_{10}\right)$ & & $0.04(.05)$ & $0.719(909)$ & .472 \\
\hline Self-Concept $\left(\gamma_{11}\right)$ & & $-0.06(.05)$ & $-1.16(909)$ & .247 \\
\hline $\operatorname{Pedagogy}\left(\gamma_{12}\right)$ & & $0.22(.11)$ & $1.96(909)$ & .051 \\
\hline $\operatorname{Content}\left(\gamma_{13}\right)$ & & $0.19(.10)$ & $1.91(909)$ & .057 \\
\hline \multicolumn{5}{|c|}{ Model for Achievement slope $\left(\beta_{2}\right)$} \\
\hline Intercept $\left(\gamma_{20}\right)$ & & $0.25(.12)$ & 2.12(909) & .034 \\
\hline \multicolumn{5}{|c|}{ Model for Ethnicity slope $\left(\beta_{3}\right)$} \\
\hline Intercept $\left(\gamma_{30}\right)$ & & $0.04(.09)$ & $0.48(909)$ & .635 \\
\hline Random Effects & Variance & df $\chi^{2}$ & $p$ & \\
\hline Var. in class means $\left(\tau_{00}\right)$ & 0.143 & 229.25 & & \\
\hline Var. within classes $\left(\sigma^{2}\right)$ & 0.652 & & & \\
\hline
\end{tabular}

Summary of Research Question 2 results. Research Question 2 asked whether there were differences between girls and boys in the relationship of their academic engagement and teacher self-perceptions. The results shown above indicate that there is, in fact, a significantly different relationship between teacher self-perceptions and behavioral engagement for boys and girls. Teacher mathematics self-concept $\left(\gamma_{11}=-.07\right.$, $t[54]=-2.14, p=.037)$ and self-efficacy for teaching mathematics content $\left(\gamma_{13}=.22\right.$, $t[54]=3.24, p=.002$ ) both significantly predicted the differential between boys and girls in their behavioral engagement scores, explaining, $61.5 \%$ of the variability between classes in the gender differential in behavioral engagement. For emotional engagement, 
although there are significant differences in reported engagement between boys and girls, these differences are not explained by teacher self-perceptions.

\section{Research Question 3}

Finally, I examined models to explore whether the measures of teacher selfperceptions were significant moderators of the high-achievement status slope. To answer this question, the three teacher self-perceptions predictors were added to the achievement slope.

Behavioral engagement. The results for this model are in Table 12. The fixed effects for the teacher self-perception variables predicting the high-achievement status slope indicated the mathematics self-concept $\left(\gamma_{21}=-.001, t[852]=-.01, p=.989\right)$, selfefficacy for pedagogy in mathematics $\left(\gamma_{22}=-.10, t[852]=-.76, p=.449\right)$, and selfefficacy for teaching mathematics content $\left(\gamma_{23}=.02, t[852]=.13, p=.899\right)$ that none of the teacher self-perceptions measures were significant predictors of the high achievement slope. Because I had already predicted that the achievement slope did not vary between groups, this result was expected. 
Table 12

Contextual Model for Behavioral Engagement by Achievement Status, Answering Research Question 3

\begin{tabular}{|c|c|c|c|}
\hline Fixed effects & Coefficient(SE) & $t(\mathrm{df})$ & $p$ \\
\hline \multicolumn{4}{|c|}{ Model for mean behavioral engagement $\left(\beta_{0}\right)$} \\
\hline Intercept $\left(\gamma_{00}\right)$ & $4.12(.05)$ & $76.07(51)$ & $<.001$ \\
\hline Years $\left(\gamma_{01}\right)$ & $-0.001(.003)$ & $-0.38(51)$ & .796 \\
\hline MathBackground $\left(\gamma_{02}\right)$ & $-0.14(.08)$ & $-1.81(51)$ & .702 \\
\hline Grade $\left(\gamma_{03}\right)$ & $-0.01(.04)$ & $-0.25(51)$ & .796 \\
\hline Self-Concept $\left(\gamma_{04}\right)$ & $0.02(.03)$ & $0.73(51)$ & .467 \\
\hline Pedagogy $\left(\gamma_{05}\right)$ & $0.03(.06)$ & $0.51(51)$ & .616 \\
\hline Content $\left(\gamma_{06}\right)$ & $0.04(.06)$ & $0.70(51)$ & .487 \\
\hline \multicolumn{4}{|l|}{ Model for Gender slope $\left(\beta_{1}\right)$} \\
\hline Intercept $\left(\gamma_{10}\right)$ & $0.13(.04)$ & $3.18(57)$ & .002 \\
\hline \multicolumn{4}{|c|}{ Model for Achievement slope $\left(\beta_{2}\right)$} \\
\hline Intercept $\left(\gamma_{20}\right)$ & $0.23(.08)$ & $2.78(852)$ & .006 \\
\hline Self-Concept $\left(\gamma_{21}\right)$ & $-0.001(.07)$ & $-0.01(852)$ & .989 \\
\hline $\operatorname{Pedagogy}\left(\gamma_{22}\right)$ & $-0.10(.13)$ & $-0.76(852)$ & .449 \\
\hline $\operatorname{Content}\left(\gamma_{23}\right)$ & $0.02(.14)$ & $0.13(852)$ & .899 \\
\hline \multicolumn{4}{|c|}{ Model for Ethnicity slope $\left(\beta_{3}\right)$} \\
\hline Intercept $\left(\gamma_{30}\right)$ & $-0.11(.06)$ & $-1.93(852)$ & .054 \\
\hline Random Effects & Variance & $\chi^{2}$ & $p$ \\
\hline Var. in class means $\left(\tau_{00}\right)$ & 0.045 & 130.02 & $<.001$ \\
\hline Var. in gender slope $\left(\tau_{11}\right)$ & 0.026 & 75.17 & .036 \\
\hline Var. within classes $\left(\sigma^{2}\right)$ & 0.266 & & \\
\hline
\end{tabular}

Emotional engagement. Once again, I examined the fixed effects for each of the three predictors on the high ability slope (see Table 13). These results indicated that none of the teacher self-perceptions measures were significant predictors of the high ability slope: mathematics self-concept $\left(\gamma_{21}=.0001, t[909]=.001, p=.999\right)$, self-efficacy for pedagogy in mathematics $\left(\gamma_{22}=-.03, t[852]=-.15, p=.884\right)$, self-efficacy for teaching mathematics content $\left(\gamma_{23}=.04, t[852]=.18, p=.857\right)$. As with behavioral engagement, I had already hypothesized that the effect of achievement on engagement did not vary across groups and thus should not expect the addition of the teacher self-perceptions variables to add any new information. 
Table 13

Contextual Model for Emotional Engagement by Achievement Status, Answering Research Question 3

\begin{tabular}{|c|c|c|c|}
\hline Fixed effects & Coefficient(SE) & $t(\mathrm{df})$ & $p$ \\
\hline \multicolumn{4}{|c|}{ Model for mean emotional engagement $\left(\beta_{0}\right)$} \\
\hline Intercept $\left(\gamma_{00}\right)$ & $3.67(.10)$ & $36.68(51)$ & $<.001$ \\
\hline Years $\left(\gamma_{01}\right)$ & $-0.01(.01)$ & $-2.08(51)$ & .043 \\
\hline MathBackground $\left(\gamma_{02}\right)$ & $-0.002(.15)$ & $-0.01(51)$ & .990 \\
\hline Grade $\left(\gamma_{03}\right)$ & $0.03(.07)$ & $0.39(51)$ & .695 \\
\hline Self-Concept $\left(\gamma_{04}\right)$ & $-0.10(.06)$ & $-1.59(51)$ & .118 \\
\hline Pedagogy $\left(\gamma_{05}\right)$ & $0.12(.12)$ & $1.00(51)$ & .322 \\
\hline Content $\left(\gamma_{06}\right)$ & $0.15(.11)$ & $1.34(51)$ & .187 \\
\hline \multicolumn{4}{|c|}{ Model for Gender slope $\left(\beta_{1}\right)$} \\
\hline Intercept $\left(\gamma_{10}\right)$ & $0.04(.05)$ & $0.713(909)$ & .476 \\
\hline \multicolumn{4}{|c|}{ Model for Achievement slope $\left(\beta_{2}\right)$} \\
\hline Intercept $\left(\gamma_{20}\right)$ & $0.25(.14)$ & $1.84(909)$ & .066 \\
\hline Self-Concept $\left(\gamma_{21}\right)$ & $0.0001(.10)$ & $0.001(909)$ & .999 \\
\hline $\operatorname{Pedagogy}\left(\gamma_{22}\right)$ & $-0.03(.21)$ & $-0.15(909)$ & .884 \\
\hline $\operatorname{Content}\left(\gamma_{23}\right)$ & $0.04(.23)$ & $0.18(909)$ & .857 \\
\hline \multicolumn{4}{|c|}{ Model for Ethnicity slope $\left(\beta_{3}\right)$} \\
\hline Intercept $\left(\gamma_{30}\right)$ & $0.06(.09)$ & $0.69(909)$ & .492 \\
\hline Random Effects & Variance & $\chi^{2}$ & $p$ \\
\hline Var. in class means $\left(\tau_{00}\right)$ & 0.144 & 227.53 & $<0.001$ \\
\hline Var. within classes $\left(\sigma^{2}\right)$ & 0.660 & & \\
\hline
\end{tabular}

Summary of Research Question 3 results. Research Question 3 asked whether teacher self-perceptions explained the difference in academic engagement between students of differing achievement status. The tables and results discussed above indicate that there is no significant relationship with any of the teacher self-perceptions variables and the high-achievement status slope for either emotional or behavioral engagement. Although there is a difference in reported engagement between students identified as high achieving and those who are not, this difference does not vary between classes and, therefore, teacher self-perceptions do not moderate this difference. 


\section{CHAPTER V \\ DISCUSSION}

The purpose of this quantitative dissertation was to examine the relationship between teacher self-perceptions and student academic engagement in mathematics. In this study, I examined that relationship in general and further studied how that relationship differed between boys and girls as well as between high-achieving students and those students who are not high-achieving. Through the use of HLM, I developed and tested a series of models to explore these relationships. These analyses highlighted some key findings of interest and also showed where some of the knowledge gaps in the study of student academic engagement remain. This section discusses the key findings of this research project and then explains the limitations and recommendations for future research.

\section{Key Findings and Implications}

In large part and with one notable exception that will be discussed, in this study I found that teacher self-perceptions are not significantly related to student academic engagement in mathematics. This might be seen as a positive result in many ways. Particularly for emotional engagement in mathematics, although reported levels of engagement did vary across classes, that variance was not directly related to the teachers' self-perceptions. Though some teachers do not have a high level of self-concept in their own mathematics ability, this does not appear to relate to how much their students report being emotionally engaged in class. 
However, there was one key finding that poses additional implications. When it comes to behavioral engagement in mathematics class, arguably a characteristic that might be particularly influenced by teachers, girls and boys differ significantly not only in their engagement (with girls reporting statistically significantly more engagement than boys) but also in the way in which their engagement relates to teacher self-perceptions. In fact, teacher self-perceptions account for approximately $62 \%$ of the difference between girls and boys on their reported levels of behavioral engagement. This finding is of particular interest for teachers and teacher educators alike and might yield some valuable information to those who are working with students. This key finding is explored more fully in the following paragraphs.

In looking back at the existing literature cited in Chapter II, it was hypothesized that teachers who report higher levels of self-perceptions might be more inclined to incorporate a variety of teaching strategies or class activities that could serve to better involve students in their mathematics class. It is interesting, and somewhat unexpected, that this relationship (i.e., the one between teacher self-perceptions and student behavioral engagement) was only related to the differential for girls rather than relating to engagement for the sample as a whole. However, this relationship does offer some thought-provoking information for those tasked with educating students in mathematics. Given that fewer girls persist in mathematics education beyond what is required, which may be due to a lack of behavioral engagement, it appears that one thing that might account for the difference in girls who do persist is the self-perception level of teachers of those girls. 
Additionally, in Chapter II I noted that, although girls and boys tend to have similar mathematics perceptions early in their education, girls tend to be less engaged in the sciences (including mathematics) than boys by the time that they reach middle school (Rinn et al., 2008). In this study of younger students, girls actually reported significantly higher behavioral engagement than boys did when placed in a classroom with a teacher who had a high level of self-efficacy for teaching mathematics content. This suggests there might be something worth exploring in the teacher/student relationship. Other researchers have suggested that girls respond more positively to STEM subjects when they see strong female role models (Teo, 2014). Given that the majority of teachers in this study were women, this idea might account for some of the differential between boys and girls when the teacher is more self-efficacious about their ability to teach mathematics concepts. Despite many efforts to decrease the size of the difference between boys and girls who enter STEM fields (i.e. there are far more males than females studying and working in mathematics and science), there is still a large gap in the STEM subjects (Teo, 2014). Thus, the results of this study support the theory that, if one is interested in helping close the STEM gap for girls, there is a need for more mathematically strong female teachers, even in the early grades.

Also, this suggests a need for teacher educators not to focus solely on elementary school mathematics teachers' mathematics self-concept but on their self-efficacy for teaching mathematics content. With the recognition that content knowledge is critical for teachers, this study also suggests that there might be benefit for teacher educators to work with teachers on their own self-efficacy in pedagogical content knowledge. In teacher education programs and professional development for elementary school teachers, 
professionals might consider focusing on mathematics pedagogical content knowledge, that is, teacher's knowledge in how to teach mathematics, rather than focusing as heavily on their mathematics knowledge itself. Knowing mathematics and knowing how to teach mathematics are two different knowledge bases (Tschannen-Moran, Hoy, \& Hoy, 2015), and this study suggests that when teachers have a stronger self-efficacy in their ability to teach mathematics, their female students report being more engaged in mathematics class.

There was also a small but significant negative relationship between teacher mathematics self-concept and the gender differential in behavioral engagement. That is, when girls were in a class with a teacher with higher mathematics self-concept, they tended to score slightly lower than boys in the same class. Lower levels of mathematics self-concept in teachers have been shown to be strongly correlated to higher levels of mathematics anxiety (Briley, 2015) and also correlated to more negative feelings toward mathematics (Austin, Wadlington, \& Bitner, 1992). These teacher beliefs have effects on student academic engagement (Ganotice \& King 2014). Moreover, girls are more likely than boys to take on the attitudes of teachers or peers (Leaper, Farkas, \& Brown, 2012). This might account for some of the differential in behavioral engagement for girls who are in a class with a teacher of lower self-concept in mathematics.

\section{Limitations}

Although attempts were made to control a number of different aspects so as to create a study that could be widely generalized, there are still some limitations. Two main limitations affect the generalizability of this study: the lack of ethnic diversity of students, 
the small number of high-achieving students, and lack of variation in how students were grouped (i.e., homogeneously or heterogeneously grouped).

The first major limitation of the study was the general homogeneity of students in relation to their ethnicity. Students in this study were chosen by convenience sampling. Although a variety of schools in several districts were used for participation, the overall sample remained overwhelmingly white. Of the student participants included in the study, roughly $80 \%$ of them were white. This percentage increased in the analytic sample to $84 \%$, largely due to the fact that teachers in the most ethnically-diverse schools were also the ones who did not complete the teacher questionnaires and, thus, teachers and students were removed from the sample. The small number of underrepresented minority students (i.e., blacks and Hispanics) limits the overall generalizability of the study. Additionally, although the study is strengthened by the use of multiple imputation for some data, because of the use of listwise deletion to remove some students from analysis (those whose teacher did not report either the student or the teacher demographics), obtaining a representative sample was not possible.

The second main limitation of the study relates to the question of measuring differences in reported academic engagement for students who are high achievers. The difficulties here are of two types. First, a relatively small number (only 70 students of the analytic sample) were identified as high achieving. This small number of students might have limited the power available to identify differences among them. In addition to the problem of the somewhat small sample size for this group, a second limitation regarding high-achieving students relates to the fact that the differential in engagement for those students surveyed did not significantly vary across different classes. The high-achieving 
students in this sample were largely from classes that were of mixed ability. This fact might account for lack of variability between classes in that differential, and the small sample size $(n=4)$ of high-ability grouped classes might contribute even further. The big-fish-little-pond effect (BFLPE; Marsh, 1987) is the phenomena by which it has been shown that student self-concept in high ability students is affected when students are

placed in ability-grouped settings. In general, when students of high ability are placed with other students of high ability, their reported academic self-concept decreases (Marsh, 1987). This effect exists across other student affective characteristics (e.g., boredom) as well (Preckel, Götz, \& Frenzel, 2010). As there are high correlations between boredom and academic engagement, it is possible that that BFLPE also occurs in relation to student engagement. Thus, this study could have benefited from more variability in the grouping of high-ability students.

\section{Future Research}

The conclusion of this study does not indicate the conclusion of research needed in this area of study; it only suggests some areas that might be interesting in the future. There are two main types of questions that might follow directly from this study. The first vein of questioning arises from the findings on where variability does or does not exist between classes and what might be some of the factors that can explain that variability. The second source of future research stems from the conclusion that teacher selfperceptions do, in fact, correlate with the gender differential in student academic engagement. This section will describe some possible research threads that could follow from this study. 
In looking at the variability between classes, there are two areas that are of particular interest: those instances where variability exists and those instances where it does not. First, student-reported levels of academic engagement do, in fact, vary across classes, although this study shows that teacher self-perceptions do not explain very much of this variability for either type of engagement. This then leaves the question of what class-level characteristics might account for this significant variation. In particular, future research should focus on those malleable class characteristics, in other words, those characteristics that might be affected by teachers or schools (e.g., ability-grouping, classroom structure, or teaching styles).

Second, high-achieving students did show a significant differential from nonhigh-achieving students in their reported level of academic engagement, but that differential in engagement did not vary across classes. That indicates that future research on student academic engagement among high-achieving students might benefit from focusing on student-level characteristics, such as mathematics interest, perceived usefulness, or self-concept. Also, as mentioned above in the limitations section, this lack of variability between classes might be due to the fact that the majority of the highachieving students in this study were in classes of mixed ability. A future study might focus on comparing students who are ability-grouped to those who are not in an attempt to explore if this lack of variance exists between those groups as well. Thus, subsequent studies on student academic engagement need to further explore sources of variability between classes.

The second area of future research stems directly from the fixed effects of this study (the relationships between the variables). Results of this study indicated that 
teacher self-perceptions are significantly related to the difference between girls and boys on reported behavioral engagement. Future studies are needed to explore the differences between what teachers of high self-perceptions and those with low self-perceptions are doing differently in their classrooms that might affect this relationship. As this was a regression analysis, causation is not possible to ascertain and the direction of the relationship is not identified. Furthermore, quantitative research offers little in the way of actually exploring what is going on in classrooms that might help to explain the gender differential in teachers with differing levels of self-perceptions. Possibly mixed methodology could be employed for the analysis of observational data in classrooms that might help understand the differences in these classrooms. Additionally, further research on girls and boys is needed to examine other perceptions of students, through interviews or other measures, which might help to explain why girls and boys are engaged differently with different types of teachers. Consequently, viewing this study through the dynamic lens of social cognitive theory, one might also question how the level of student engagement in a class might affect the teacher's self-perceptions.

More can be learned about the way in which student academic engagement is experienced outwardly in the classrooms. In this dissertation, I focused on the psychological construct of engagement, which is inherently a self-report measure of how a student experiences the class and themselves in the classroom environment. Because behavioral engagement (the one area where significant results were found) is actually intended to be a measure of how they participate in class, measuring observable indicators of engagement (e.g., asking relevant questions, participating in activities, answering questions posed by the teacher and peers) as opposed to student-reported 
engagement might be of interest. Future research might employ observations or secondary reporters (e.g., teachers) to see if students who indicate that they are more engaged are outwardly engaged in class in productive ways. This might help teachers and administrators better understand ways in which students might be better engaged, in particular, given the differences in the engagement levels of girls and boys.

A final, yet not unexpected finding of this study pertains to gifted students. This study found that gifted students in each class reported higher levels of both behavioral and emotional engagement. This leads one to question whether teachers are gearing instruction toward those students who are high achievers or whether the status as high achievers has in some way affected their classroom engagement. The fact that this occurs across all classes and is not moderated by the any of classroom or teacher characteristics, suggests that this is implicit in the school systems and not unique to particular teachers. More needs to be done to help engage the other students (i.e. the non high achieving students) in the mathematics classrooms.

This study has shown that students do vary on their levels of academic engagement. As student academic engagement is shown to be correlated to achievement (Fredricks et al., 2004), continued studies need to explore both class-/teacher- and student-level factors that might moderate the level of engagement to support the creation of classroom environments most conducive to student participation and, ultimately, increased achievement. Clearly this shows a need for teachers who are confident in their mathematical ability, and who also possess strong mathematics pedagogy and content knowledge. 


\section{Conclusion}

In conclusion, student academic engagement in mathematics, both behavioral and emotional, does differ across classes. This means that there are things at the class-level that are related to student academic engagement. Given that engagement is understood to be malleable and affected by environment, this study gives strong evidence that there is more to learn about the ways in which teachers or classroom environments can help to increase academic engagement. Additionally, behavioral engagement shows significant differential between boys and girls and that a great deal of this variability can be explained by the teacher self-perceptions. This suggests that, in an effort to retain more girls in the STEM fields (mathematics, in particular, as shown in this study) there may be a need for teachers who are highly self-efficacious in teaching mathematics. This might help to engage female students in the subject and then retain them in the STEM pipeline. As pointed out in the introduction to this dissertation, developing and refining mathematics education is of critical import for students, and there is still a great deal that can be learned about how best to educate students in mathematics (National Research Council, 2007) and retain students in mathematical fields (Teo, 2014). 


\section{REFERENCES}

Adams, C., Chamberlin, S., Gavin, M. K., Schultz, C., Sheffield, L. J., \& Subotnik, R. (2008). The STEM promise: Recognizing and developing talent and expanding opportunities for promising students of science, technology, engineering and mathematics. Washington, DC: National Association for Gifted Children.

Appleton, J. J., Christenson, S. L., Kim, D. \& Reschly, A. L. (2006) Measuring cognitive and psychological engagement: Validation of the student engagement instrument. Journal of School Psychology, 44, 427 - 445.

Austin, S., Wadlington, E., \& Bitner, J. (1992). Effect of beliefs about mathematics on math anxiety and math self-concept in elementary teachers. Education, 112, 390396.

Bandura, A. (1977). Self-efficacy: toward a unifying theory of behavioral change. Psychological Review, 84, $191-215$.

Bebell, D., \& O’Dwyer, L.M. (2010). Educational outcomes and research from 1:1 computing settings. Journal of Technology, Learning and Assessment, 9. Retrieved October 2, 2012 from http://jtla.org.

Betts, J. (2012). Issues and methods in the measurement of student engagement: Advancing the construct through statistical modeling. In S. L. Christenson, A. L. Reschly, C. Wylie (Eds.), Handbook of research on student engagement (pp. 783803). New York, NY: Springer Science. 
Bong, M., \& Skaalvik, E. M. (2003). Academic self-concept and self-efficacy: How different are they really? Educational Psychology Review, 15, 1-40.

Bouck, E. C., \& Flanagan, S. M. (2010). Virtual manipulatives: What they are and how teachers can use them. Intervention in School and Clinic, 45, 186-191.

Briley, J. S. (2012). The relationships among mathematics teaching efficacy, mathematics self-efficacy, and mathematical beliefs for elementary Pre-service teachers. Issues in the Undergraduate Mathematics Preparation of School Teachers, 5.

Cash, K. M, Adelson, J. L, \& Robinson, A. E. (2015, April). Academic Engagement in STEM: Development of the STEM Engagement Scale. Paper presented at the University of Louisville Spring Research Conference, Louisville, KY.

Cash, K. M., \& Adelson, J. L. (2015). Student Engagement Scale. Instrument in development.

Cerezo, N. (2004). Problem-based learning in the middle school: A research case study of the perceptions of at-risk females. RMLE Online: Research in Middle Level Education, 27, 1-13.

Cohen, B.H. (2008). Explaining Psychological Statistics: Third Edition. Hoboken, NJ: Wiley.

Cohen, J. (1990). Things I have learned (so far). American Psychologist, 45, 1304-1312.

Debnath, L. (2011). A brief historical development of classical mathematics before the Renaissance. International Journal of Mathematical Education in Science and Technology, 42, 625-647.

Dede, C. (2000). Emerging influences of information technology on school curriculum. Journal of Curriculum Studies, 32, 282 - 303. 
Dellinger, A. B., Bobbett, J. J., Olivier, D. F., \& Ellett, C. D. (2008). Measuring teachers' self-efficacy beliefs: Development and use of the TEBS-Self. Teaching and Teacher Education, 24, 751-766.

Dong, N., and Maynard, R. A., with Hofer, K. G. (2011). "PowerUp: a Tool for Calculating Minimum Detectable Effect Size for Experimental and QuasiExperimental Designs." Presented at the Symposium on Design Considerations for Experimental Studies in Education (Spyros Konstantopoulos, Chair) at the 2011 Annual Meeting of the American Educational Research Association, New Orleans, Louisiana.

Eccles, J. S., \& Wigfield, A. (2002). Motivational beliefs, values, and goals. Annual review of psychology, 53, 109-132.

Eddy, C. M., Fuentes, S. Q., Ward, E. K., Parker, Y. A., Cooper, S., William, A. J., Mallam, W. A., Sorto, M. A., \& Wilkerson, T. L. (2015). Unifying the algebra for all movement. Journal of Advanced Academics, 26, 59 - 92.

Ellington, A. J. (2003). A meta-analysis of the effects of calculators on students' achievement and attitude levels in precollege mathematics classes. Journal for Research in Mathematics Education, 30, 433-463.

Engel, G., \& Green, T. (2011). Cell phones in the classroom: Are we dialing up disaster? TechTrends: Linking Research \& Practice to Improve Learning, 55, 39 - 45.

Faul, F., Erdfelder, E., Lang, A.-G., \& Buchner, A. (2007). G*Power 3: A flexible statistical power analysis program for the social, behavioral, and biomedical sciences. Behavior Research Methods, 39, 175-191. 
Fredricks, J. A., Blumenfeld, P. C., \& Paris, A. H. (2004). School engagement: Potential of the concept, state of the evidence. Review of Educational Research, 74, 59-109.

Fredricks, J. A., \& McColskey, W. (2012). The measurement of student engagement: A comparative analysis of various methods and student self-report instruments. In S.

L. Christenson, A. L. Reschley, C. Wylie (Eds.) Handbook of Research on Student Engagement (763-782). New York, NY: Springer Science.

Fredricks, J. McColskey, W., Meli, J., Mordica, J., Montrosse, B., Mooney, K., \& Regional Educational Laboratory Southeast, (2011). Measuring student engagement in upper elementary through high school: A description of 21 instruments. Issues \& Answers, REL 2011 - No. 098, Regional Educational Laboratory Southeast.

Ganotice Jr, F. A., \& King, R. B. (2014). Social influences on students' academic engagement and science achievement. Psychological Studies, 59, 30-35.

Gasser, K. W. (2011). Five ideas for $21^{\text {st }}$ century math classrooms. American Secondary Education, 39, 108-116.

Glanville, J. L., \& Wildhagen, T. (2007). The measurement of school engagement: Assessing dimensionality and measurement invariance across race and ethnicity. Educational \& Psychological Measurement, 67, 1019 - 1041.

Goddard, R. D., Hoy, W. K., \& Hoy, A. W. (2000). Collective teacher efficacy: Its meaning, measure, and impact on student achievement. American Educational Research Journal, 37, 479-507.

Green, J., Liem, G. A. D., Martin, A. J., Colmar, S., Marsh, H. W., \& McInerney, D. (2012). Academic motivation, self-concept, engagement, and performance in high 
school: Key processes from a longitudinal perspective. Journal of Adolescence, 35, 1111-1122.

Green, J., Martin, A. J., \& Marsh, H. W. (2007). Motivation and engagement in English, mathematics and science high school subjects: Towards an understanding of multidimensional domain specificity. Learning and Individual Differences, 17, 269-279.

Gresalfi, M. S. (2009). Taking up opportunities to learn: Constructing dispositions in mathematics classrooms. The Journal of the Learning Sciences, 18, 327-369.

Haapsalo, L. (2007). Adapting mathematics education to the needs of ICT. The Electronic Journal of Mathematics and Technology, 1, $1-10$.

Halat, E. (2008). The effects of designing Webquests on the motivation of pre-service elementary school teachers. International Journal of Mathematical Education in Science and Technology, 39, 793-802.

Henningsen, M. \& Stein, M. K. (1997). Mathematical tasks and student cognition: Classroom-based factors that support and inhibit high-level mathematical thinking and reasoning. Journal for Research in Mathematics Education, 28, 524-549.

Hill, H. C., Rowan, B., \& Ball, D. L. (2005). Effects of teachers' mathematical knowledge for teaching on student achievement. American Educational Research Journal, 42, 371-406.

Hudson, B., Henderson, S., \& Hudson, A. (2015). Developing mathematical thinking in the primary classroom: liberating students and teachers as learners of mathematics. Journal of Curriculum Studies, 47, 374-398. 
Hung, W., Jonassen, D. H., \& Liu, R. (2008). Problem-based learning. Handbook of Research on Educational Communications and Technology, 3, 485-506.

Jerzembek, G., \& Murphy, S. (2013). A narrative review of problem-based learning with school-aged children: Implementation and outcomes. Educational Review, 65, 206-218.

Kim, H. Y. (2013). Statistical notes for clinical researchers: Assessing normal distribution (2) using skewness and kurtosis. Restorative Dentistry \& Endodontics, 38, 52-54.

Kissane, B. (2007) Exploring the place of hand-held technology in secondary mathematics education. In:12th Asian Technology Conference on Mathematics, Taipei, Taiwan.

Kranzler, J. H., \& Pajares, F. (1997). An Exploratory Factor Analysis of the Mathematics Self-Efficacy Scale Revised (MSES-R). Measurement and Evaluation in Counseling and Development, 29, 215-228.

Lange, P. L. (2010). Teacher perceptions and student achievement related to inquirybased mathematics (Order No. 3427697). Available from ProQuest Dissertations \& Theses Global. (815238166). Retrieved from http://search.proquest.com/docview/815238166?accountid=14665.

Leaper, C., Farkas, T., \& Brown, C. S. (2012). Adolescent girls' experiences and genderrelated beliefs in relation to their motivation in math/science and English. Journal of Youth and Adolescence, 41, 268-282.

Lee, J. (2014). The relationship between student engagement and academic performance: Is it a myth or reality? The Journal of Educational Research, 107, 177 - 185. 
Levpuscek, M. P., Zupancic, M., \& Socan, G. (2012). Predicting achievement in mathematics in adolescent students: The role of individual and social factors. Journal of Early Adolescence, 33, 523 - 551.

Li, Q. \& Ma, X. (2003). A Meta-analysis of the Effects of Computer Technology on School Students' Mathematics Learning. Educational Psychology Review, 22, $215-243$.

Marsh, H. W. (1987). The big-fish-little-pond effect on academic self-concept. Journal of Educational Psychology, 79, 280.

Marsh, H. W., \& Byrne, B. M. (1993). Do we see ourselves as others infer: A comparison of self-other agreement on multiple dimensions of self-concept from two continents. Australian Journal of Psychology, 45, 49-58.

Marsh, H. W., \& O'Neill, R. (1984). Self description questionnaire III: The construct validity of multidimensional self-concept ratings by late adolescents. Journal of Educational Measurement, 21(2), 153-174.

Maxwell, S. E. (2000). Sample size and multiple regression analysis. Psychological Methods, 5, $434-458$.

McCoach, D. B., \& Adelson, J. L. (2010). Dealing with dependence (Part I): Understanding the effects of clustered data. Gifted Child Quarterly, 54(2), 152155.

McGee, J. R., \& Wang, C. (2014). Validity-supporting evidence of the self-efficacy for teaching mathematics instrument. Journal of Psychoeducational Assessment, 32, 390-403. 
McKnight, P. E., McKnight, K. M., Sidani, S., \& Figueredo, A. J. (2007).Missing data: A gentle introduction. New York, NY: Guilford Press.

Middleton, J. A., \& Spanias, P. A. (1999). Motivation for achievement in mathematics: Findings, generalizations, and criticisms of the research. Journal for Research in Mathematics Education,30, 65-88.

Mifsud, L., \& Mørch $\dagger$, A. I. (2010). Reconsidering off-task: A comparative study of PDA-mediated activities in four classrooms. Journal of Computer Assisted Learning, 26, 190-201.

Muthén, L., \& Muthén, B. (1998 - 2010). Mplus user's guide $\left(6^{\text {th }}\right.$ ed.). Los Angeles, CA: Muthen \& Muthen.

National Council of Teachers of Mathematics (2012). Mission and vision statements. Retrieved from https://www.nctm.org/About/.

NRC (2007). Rising above the gathering storm. http://www.nap.edu/openbook.php?record_id=11463\&page= 1

Nguyen, D. M., Hsieh, Y. J, Allen, G. D (2006). The impact of web-based assessment and practice on students' mathematics learning attitudes. The Journal of Computers in Mathematics and Science Teaching, 25, 251 - 279.

Nosek, B. A., \& Smyth, F. L. (2011). Implicit social cognitions predict sex differences in math engagement and achievement. American Educational Research Journal, 48, $1125-1156$.

Nurlu, Ö. (2015). Investigation of teachers' mathematics teaching selfefficacy. International Electronic Journal of Elementary Education, 8, 21. 
Oates, G. (2009). Relative values of curriculum topics in undergraduate mathematics in an integrated technology environment. In R. Hunter, B. Bicknell, \& T. Burgess (Eds.), Crossing divides: Proceedings of the 32nd annual conference of the Mathematics Education Research Group of Australasia (Vol. 2; pp. 419-426). Palmerston North, NZ: MERGA. Retrieved from http://www.merga.net.au/documents/Oates_RP09.pdf

OECD (2013). Results from PISA 2012, United States Country Note. http://www.oecd.org/pisa/keyfindings/PISA-2012-results-US.pdf.

Pajares, F., \& Miller, M. D. (1994). Role of self-efficacy and self-concept beliefs in mathematical problem solving: A path analysis. Journal of Educational Psychology, 86, 193 - 203.

Preckel, F., \& Brüll, M. (2008). Grouping the gifted and talented: Are gifted girls most likely to suffer the consequences? Journal for the Education of the Gifted, 32, 5485.

Preckel, F., Götz, T., \& Frenzel, A. (2010). Ability grouping of gifted students: Effects on academic self-concept and boredom. British Journal of Educational Psychology, 80(3), 451-472.

Puchner, L. Taylor, A., O'Donnell, B., \& Fick, K. (2008). Teacher learning and mathematics manipulatives: A collective case study about teacher use of manipulatives in elementary and middle school mathematics lessons. School Science and Mathematics, 108, 313-325.

Rapp, W. H. (2009). Avoiding math taboos: Effective math strategies for visual-spatial learners. TEACHING Exceptional Children Plus, 6(2). 
Raudenbush, S. W., et al. (2011). Optimal Design Software for Multi-level and Longitudinal Research (Version 3.01) [Software]. Available from www.wtgrantfoundation.org.

Raudenbush, S., \& Bryk, A. (2002). Hierarchical linear models (2nd ed.). Newbury Park, CA: Sage.

Rinn, A. N., \& Cunningham, L. G. (2008). Using self-concept instruments with highability college students: Reliability and validity evidence. Gifted Child Quarterly,52, $232-242$.

Rinn, A. N., McQueen, K. S., Clark, G. L., \& Rumsey, J. L. (2008). Gender differences in gifted adolescents' math/verbal self-concepts and math/verbal achievement: Implications for the STEM fields. Journal for the Education of the Gifted, 32, 3453.

Rodrigo, M. T. (2011). Dynamics of student cognitive-affective transitions during a mathematics game. Simulation \& Gaming, 42, 85-99.

Ross, J. A. (1992). Teacher efficacy and the effects of coaching on student achievement. Canadian Journal of Education,17, 51-65.

Ruthven,K., Deaney, R., Hennesy, S (2009). Using graphing software to teach about algebraic forms: A study of technology-supported practice in secondary-school mathematics. Educational Studies in Mathematics, 71(3), 279 - 297.

Ryan, R. M., \& Deci, E. L. (2000). Intrinsic and extrinsic motivations: Classic definitions and new directions. Contemporary Educational Psychology, 25, 54-67. 
Schoenfeld, A. H. (1992). Learning to think mathematically: Problem solving, metacognition, and sense making in mathematics. Handbook of research on mathematics teaching and learning, 334-370.

Singh, K., Granville, M., \& Dika, S. (2002). Mathematics and science achievement: Effects of motivation, interest, and academic engagement. The Journal of Educational Research, 95, 323 - 332.

Smith, L. J. (2010). The relationship among mathematics anxiety, mathematical selfefficacy, mathematical teaching self-efficacy, and the instructional practices of elementary school teachers (Order No. 3437912). Available from ProQuest Dissertations \& Theses Global. (821688482). Retrieved from http://search.proquest.com/docview/821688482?accountid=14665

Stevens, T., Aguirre-Munoz, Z., Harris, G., Higgins, R., \& Liu, X. (2013). Middle level mathematics teachers' self-efficacy growth through professional development: Differences based on mathematical background. Australian Journal of Teacher Education, 38, $144-164$.

Teo, T. W. (2014). Hidden currents in the STEM pipeline: Insights from the dyschronous life episodes of a minority female STEM teacher. Theory Into Practice, 53, 48-54.

Trautwein, U., Lüdtke, O., Marsh, H. W., Köller, O., \& Baumert, J. (2006). Tracking, grading, and student motivation: Using group composition and status to predict self-concept and interest in ninth-grade mathematics. Journal of Educational Psychology, 98, 788 - 806. 
Trinter, C. P., Moon, T. R., \& Brighton, C. M. (2015). Characteristics of students' mathematical promise when engaging with problem-based learning units in primary classrooms. Journal of Advanced Academics, 26, 24-58.

Tschannen-Moran, M., Hoy, A. W., \& Hoy, W. K. (1998). Teacher efficacy: Its meaning and measure. Review of Educational Research, 68, 202-248.

Wang, Z., Bergin, C., \& Bergin, D. A. (2014). Measuring engagement in fourth to twelfth grade classrooms: The Classroom Engagement Inventory. School Psychology Quarterly, 29, 517.

Wood, E. F. (1988). Math anxiety and elementary teachers: What does research tell us? For the Learning of Mathematics, 8, 8-13. 
Appendix A

\section{Teacher Demographic Survey}

1. Gender: Male

Female

2. Which of the following best describes you? (You may check more than one.)

White

Black

Asian/Pacific Islander

Hispanic

Native American / Alaskan Native

Other

3. Including this year, how many years have you taught?

4. In your undergraduate program did you have

a. a major or minor in mathematics?

Yes No

b. an emphasis or endorsement in mathematics education? Yes No

5. In your graduate program did you earn a degree in mathematics or mathematics education?

Yes

No

I have not earned a graduate degree 


\title{
CURRICULUM VITAE
}

\section{Kathleen Marie Cash}

\author{
University of Louisville \\ College of Education and Human Development \\ Phone: (502) 721-8222
}

\section{Education}

Ph. D. in Curriculum and Instruction, University of Louisville, Louisville, KY. Specialization: Mathematics Education

Dissertation: Teacher Self-perceptions and student academic engagement in Elementary School Mathematics.

August, 2016.

M. Ed. in Teacher Leadership, University of Louisville, Louisville, KY. Specialization: Mathematics Education.

Action Research Project: A Comparative Look at Mobile Technology in the Mathematics Classroom.

May, 2012.

B. S. in Mathematics, Brescia University, Owensboro, KY.

Certification in Mathematics Education.

Senior Thesis: Connecting the Dots: On the Graph-theoretical Thickness of the Complete Bipartite Graph.

May, 2004.

\section{Professional Experience}

Graduate/Research Assistant Dr. Jill Adelson, Educational Psychology, Measurement, and Evaluation Program, University of Louisville, 2015.

Co-Teacher Elementary Mathematics Methods course, University of Louisville, Louisville, KY, Fall 2014. 
Teacher Mathematics teacher, grades 9 - 12, Trinity High School, Louisville, KY, 2008 -2015.

Teacher Mathematics teacher, grades 7 - 12, Forest Park High School, Ferdinand, IN, 2007-2008.

\section{Publications}

Adelson, J. L., Harbour, K., Cash, K. M., \& Pittard, C. (October, 2015). Magnifying Math in the Middle. Report submitted to Kentucky Center for Mathematics.

\section{Presentations}

Cash, K.M., Adelson, J. L., \& Robinson, A. (April, 2016). Development of the Science and Math Engagement Scale. Paper at the 2016 American Educational Research Association Annual Meeting and Exhibition, Washington, DC.

Cash, K.M. (November, 2015). Ability grouping and mathematics affect. Paper presented at the $62^{\text {nd }}$ Annual Convention of the National Association for Gifted Children, Phoenix, AZ.

Cash, K.M., Adelson, J. L. (April, 2015). Development of the Student Engagement Scale in Science, Engineering, and Mathematics. Paper presented at the Joint Spring Research Conference of University of Louisville, University of Kentucky, and University of Cincinnati.

\section{Professional Service}

Reviewer Journal of Educational Researcher, 2015.

\section{Professional Memberships}

American Educational Research Association

National Council for Teachers of Mathematics

National Association for Gifted Children 


\begin{abstract}
Awards
$3^{\text {rd }}$ Place for In-Progress Doctoral Research - Student Research Gala, National Association for Gifted Children, 2015.
\end{abstract}

Outstanding Graduating Student Award, University of Louisville, 2012. 